Review Article

\title{
Meta-Analysis of Therapy of Cinobufacini Capsule Adjunct with First-Line Platinum-Based Chemotherapy for the Treatment of Advanced NSCLC
}

\author{
Wenpan Peng, ${ }^{1}$ Yong Xu ${ }^{D},{ }^{1}$ Fanchao Feng, ${ }^{1,2}$ Cheng Gu, ${ }^{1}$ Zhichao Wang, ${ }^{1}$ Di Han, ${ }^{1}$ \\ Xianmei Zhou $\mathbb{D}^{1,2}$ and Hailang $\mathrm{He} \mathbb{D}^{1,2}$ \\ ${ }^{1}$ Affiliated Hospital of Nanjing University of Chinese Medicine, Nanjing 210029, China \\ ${ }^{2}$ Department of Respiratory Medicine, Jiangsu Province Hospital of Chinese Medicine, Nanjing 210029, China
}

Correspondence should be addressed to Xianmei Zhou; zhouxianmeijs@aliyun.com and Hailang He; lyghehailang@163.com

Received 8 February 2021; Revised 11 July 2021; Accepted 11 August 2021; Published 23 August 2021

Academic Editor: Juntra Karbwang

Copyright (C) 2021 Wenpan Peng et al. This is an open access article distributed under the Creative Commons Attribution License, which permits unrestricted use, distribution, and reproduction in any medium, provided the original work is properly cited.

\begin{abstract}
Background. Cinobufacini capsule, an anticancer traditional Chinese patent medicine, has been widely used as adjunctive treatment to platinum-based chemotherapy in patients with advanced NSCLC. Purpose. To evaluate the efficacy and safety of cinobufacini capsule combined with first-line platinum-based chemotherapy for advanced NSCLC. Study Design. A systematic review and meta-analysis of eight outcome measures selected for this study were performed according to the Preferred Reporting Items for Systematic Reviews and Meta-Analyses (PRISMA) guidelines. Methods. A comprehensive literature search was conducted in 7 electronic databases to identify all the relevant randomised controlled trials. Cochrane handbook 5.1.0 was applied to evaluate the quality of included trials, and the RevMan 5.3 and Stata 15.1 software were used to combine the trials for data analysis and assess the publication bias. Results. From the 19 studies reviewed, a total of 1,564 patients were included. Compared with first-line platinum-based chemotherapy alone, cinobufacini capsule combined with chemotherapy showed significant effects in improving ORR $(\mathrm{RR}=1.49,95 \% \mathrm{CI}(1.33,1.66))$, 1-year survival rate $(\mathrm{RR}=1.44,95 \% \mathrm{CI}(1.28,1.63))$, and 2-year survival rate $(\mathrm{RR}=1.78,95 \% \mathrm{CI}(1.42,2.22))$, raising the percentages of $\mathrm{CD}^{+}$cells $(\mathrm{SMD}=1.25,95 \% \mathrm{CI}(1.05,1.45)), \mathrm{CD} 4^{+}$cells $(\mathrm{SMD}=1.52$, $95 \% \mathrm{CI}(1.33,1.71))$, and ratio of $\mathrm{CD}^{+} / \mathrm{CD}^{+}(\mathrm{SMD}=1.36,95 \% \mathrm{CI}(1.17,1.54))$, and reducing chemotherapy toxicity including leukopenia $(\mathrm{RR}=0.61,95 \% \mathrm{CI}(0.51,0.72))$, thrombocytopenia $(\mathrm{RR}=0.52,95 \% \mathrm{CI}(0.41,0.67))$, and vomiting $(\mathrm{RR}=0.79,95 \% \mathrm{CI}$ $(0.70,0.88))$. Conclusion. Cinobufacini capsule may increase the therapeutic effectiveness, improve cellular immune function, and reduce the toxicity of first-line platinum-based chemotherapy in patients with NSCLC. These results require confirmation by further rigorously designed randomised controlled trials (RCTs).
\end{abstract}

\section{Introduction}

Lung cancer is the most frequently diagnosed cancer and the leading cause of cancer-related deaths worldwide [1]. For the purposes of treatment, lung cancer is classified as SCLC and NSCLC which accounts for approximately $83 \%$ of all lung cancer cases [2]. Because early-stage NSCLC is typically asymptomatic, approximately $61 \%$ of patients with NSCLC are diagnosed at an advanced stage and lose the opportunity for surgery [3]. As a potentially curable treatment, platinumbased chemotherapy is still occupying the dominant position in the treatment for advanced NSCLC because of its effectiveness in decreasing the size of tumor [4]. However, although technology continues to advance, chemotherapy for NSCLC is still associated with low efficacy and accompanied with some adverse effects [5]. Some patients even cannot continue the therapy due to serious side effect of chemotherapy. Therefore, seeking a drug that can improve the efficacy and alleviate the toxicity of chemotherapy is extremely essential.

In complementary and alternative medicines, traditional Chinese medicine is one of the popular adjunctive treatments for lung cancer, mainly by enhancing immunity and reducing the adverse effects of chemotherapy [6, 7]. 
Cinobufacini (also called Huachansu in Chinese) capsule, a formulation of traditional Chinese medicine preparation, is produced from dried toad venom from the skin glands of Bufo and has been approved by the Chinese State Food and Drug Administration (SFDA) for the treatment of a variety of cancers [8]. Our previous systematic review has showed that cinobufacini injection as an adjuvant therapy to platinum-contained chemotherapy can increase survival rate, improve tumor response, and reduce the toxicity of chemotherapy in advanced NSCLC patients [9-11]. Studies have identified that cinobufacini, containing bufalin, resibufogenin, 5-hydroxytryptamine, etc, can inhibit proliferation, promote apoptosis, and increase immunity in the treatment of tumors [12-14].

In recent years, the number of RCTs on cinobufacini capsule combined with chemotherapy for the treatment of NSCLC has increased. A previous meta-analysis indicated that cinobufacini capsule combined with platinum-based chemotherapy might increase efficacy and alleviate the toxicity of chemotherapy for patients with NSCLC [15]. However, only seven RCTs were included in that study, and the methodological quality of the included trials was inadequate. Recently, there have emerged several new clinical trials evaluating the efficacy of cinobufacini capsule combined with platinum-based chemotherapy for NSCLC. Therefore, with an expectation to provide stronger evidence for the clinical application of cinobufacini capsule for NSCLC, this updated systematic review and meta-analysis was conducted to evaluate the efficacy and safety of cinobufacini capsule using Cochrane systemic evaluation methods, by gathering all the related studies (Figure 1).

\section{Data and Methods}

2.1. Literature Search Strategy. Four Chinese databases, including the Chinese National Knowledge Infrastructure (CNKI), Wanfang Database, Chinese Scientific Journal Database (VIP), and Chinese Biomedical Literature Database (CBM), as well as three English databases, including PubMed, Cochrane Library, and Embase, were searched for RCT literatures on the treatment of NSCLC using combined first-line platinum-based chemotherapy with cinobufacini capsule. All of those searches ended on Jul 01, 2020, and retrieval terms were "cinobufotalin capsule," "huachansu capsule," "non small cell lung cancer," "non small lung cancer," "non-small cell cancer," "non-small cell lung," "non-small cell lung cancer," "non-small cell lung cancers," "non-small-cell lung cancer," "RCT," and "randomised control." The references of pertinent publications were manually searched for additional studies.

2.2. Inclusion Criteria. Eligible studies for inclusion in the meta-analysis met the following criteria: (1) patients had to be diagnosed with NSCLC of stage III/IV by histopathological or cytological diagnostic criteria; (2) studies concerning clinical RCTs and the treatment group with cinobufotalin capsule in combination with first-line platinum-based chemotherapy and the control group with chemotherapy alone. (3) The outcome should include at least one of the following indicators: ORR, one-year survival rate, two-year survival rate, leukocyte toxicity, platelet toxicity, vomiting toxicity, $\mathrm{CD}^{+}$ level, $\mathrm{CD} 4^{+}$level, and $\mathrm{CD} 4^{+} / \mathrm{CD}^{+}$level.

2.3. Exclusion Criteria. The exclusion criteria were as follows: (1) dissertations, reviews, conference papers, or animal experiments; (2) in the experimental group, cinobufacini was the only drug of treatment; no chemotherapy or other drugs were used in addition to cinobufacini, and no first-line platinum-based chemotherapy drugs were used in the control group; (3) the research method was a nonclinical randomised controlled trial; (4) pathological diagnosis is not stage III/IV or could not be determined; and (5) outcome indicator report documents were not standardised or lacked detail.

2.4. Data Extraction and Quality Assessment. The detailed method followed the previously reported one [16]. Two investigators (Wenpan Peng and Yong $\mathrm{Xu}$ ) independently reviewed the eligible studies and extracted the data. This course was cross checked in order to ensure reliability and accuracy. The following information was collected: authors, title of study, year of publication, study size, age and sex of the participants, details of methodological information, interventions, outcomes, and adverse effects for each study. Any disagreements were resolved by consultation of two other reviewers (Hailang He and Xianmei Zhou).

The methodological quality of the included studies was evaluated independently by two reviewers (Wenpan Peng and Yong $\mathrm{Xu}$ ). According to the Cochrane handbook version 5.1.0 bias risk scoring system, random sequence generation, allocation concealment, blinding (or masking), incomplete data assessment, selective outcome reporting, and other sources of bias were assessed with three potential responses: yes, no, and unclear [17]. Any disagreements were resolved by discussion with the two other reviewers (Hailang He and Xianmei Zhou).

2.5. Outcome Measures. Primary outcome indices of efficacy were short- and long-term efficacy. The long-term efficacy was assessed by 1 - and 2-year survival rates, and the shortterm efficacy was assessed by using the judgement criteria for solid tumours from the World Health Organisation (WHO) [18], i.e., the ORR (objective response rate)= complete remission $(\mathrm{CR})+$ partial remission $(\mathrm{PR})$. The $\mathrm{CD}^{+} / \mathrm{CD}^{+}$ ratio and $\mathrm{CD}^{+}$and $\mathrm{CD}^{+}$level in $\mathrm{T}$ cells of peripheral blood lymphocytes were assessed as immune and biochemical indicators. Adverse reactions were classified according to the toxicity classification standards of the WHO and divided into grades 0-IV. Grade II-IV toxicities were considered adverse reactions [19]. Secondary outcome indices of efficacy were leukocyte and platelet toxicities, as well as vomiting in the digestive tract.

2.6. Statistical Analysis. The meta-analysis was performed using RevMan 5.3 (Copenhagen: the Nordic Cochrane Centre, the Cochrane Collaboration, 2014) and Stata 15.1 


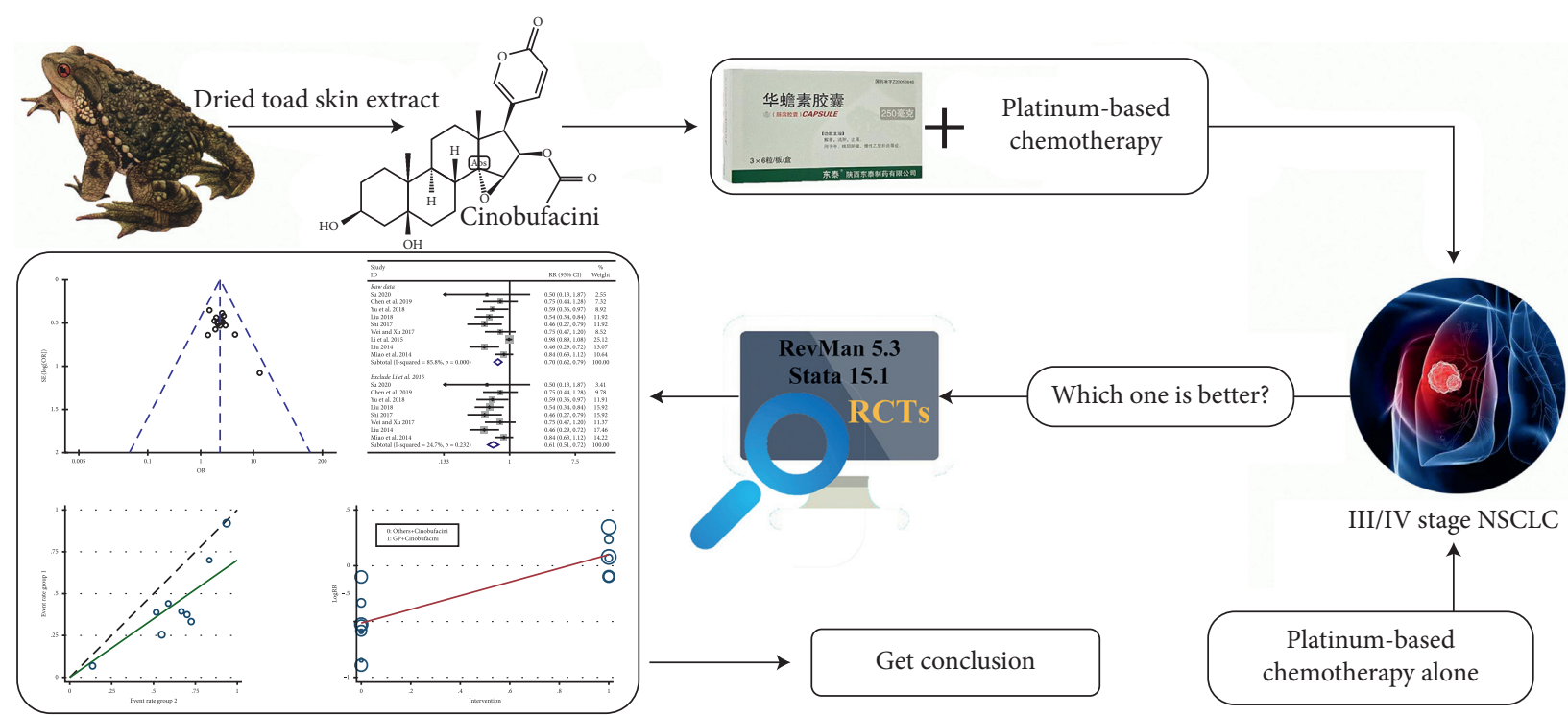

FIgURE 1: Work flow of the present study.

(Stata Corp., College Station, TX, USA). During data entry, cross checking was carried out to ensure accurate data entry. We calculated the relative risk (RR) with $95 \%$ confidence and SMD to compare dichotomous and continuous variables, respectively. Heterogeneity was assessed using Cochran's $Q$ test and Higgins' $I^{2}$ indicator, and the test level was $P>0.05$ and $I^{2}=50 \%[17,20]$. If the heterogeneity existed in pooled studies $\left(I^{2}>50 \%\right)$, the random model was applied. Otherwise, the fixed model was used. The potential publication bias was evaluated through funnel plots and assessed by Egger's test [21]. If $P>0.05$, no publication bias was present. The sensitivity was assessed through deleting the studies with high weight and significant differences.

\section{Results}

3.1. Retrieval Results. The initial search in the electronic database identified 76 potentially relevant studies. A total of 31 records were identified after removing duplicates and screening the titles and abstracts. Twelve trials were excluded for the following reasons: systematic reviews $(n=1)$, animal experiments $(n=0)$, overview $(n=1)$, inappropriate interventions $(n=7)$, non-RCTs $(n=0)$, inconformity research content $(n=2)$, and incomplete data $(n=1)$. Nineteen clinical trials were included in the final meta-analysis. A flowchart describing the literature search and study selection is shown in Figure 2.

3.2. Study Characteristics. The characteristics of the 19 RCTs comprising 1,564 patients, with 796 and 768 patients in the experimental and control groups, respectively, are summarized in Table 1 (19 RCTs). All included RCTs were conducted in China, and the articles were published from 2011 to 2020. All patients were divided into two groups, and the clinical diagnosis of all patients was stage III/IV. The intervention for the control group was first-line platinumbased chemotherapy alone, whereas the intervention for the experimental group was cinobufacini capsule combined with the first-line platinum-based chemotherapy regimen.

3.3. Study Quality. In all 19 RCTs, 17 of them referred to random number tables or random sequence methods, which were rated as "low risk" and two RCTs were grouped by treatment and rated as "high risk." None of the 19 articles mentioned allocation concealment and blindness, and the assessment was "unclear." One of the missing cases, with incomplete report results, was rated as "high risk." None of the 19 articles had selective reporting bias and were rated as "low risk." Nineteen articles could not be judged for othersource biases and were rated as "unclear," as shown in Figures 3 and 4 .

3.4. Evidence Quality Evaluation. The outcome indicators in this study were graded by using the GRADE evaluation tool. Since all the studies included in this analysis were randomised controlled studies, which were preset to the highest level in the evaluation tool, the quality of the evidence should be considered according to the five downgrade factors. Due to the risk of bias in random concealment, blind, insufficient sample size, and other factors, the outcome indicators were considered to be downgraded, as shown in Table 2 .

\subsection{Meta-Analysis}

3.5.1. ORR. The summary of the meta-analysis is listed in Table 3. The ORR was reported in 17 research articles [22-29, 31-39] with a total of 1,445 patients, including 735 and 710 cases in the cinobufacini capsule plus chemotherapy and chemotherapy alone groups, respectively. The heterogeneity test result was $P>0.05$ and $I^{2}=0.0 \%$, suggesting that no heterogeneity was observed among the results (Figure 5(a)); therefore, the fixed-effect model was applied to combine the trials $(\mathrm{RR}=1.49,95 \% \mathrm{CI}(1.33,1.66))$. 


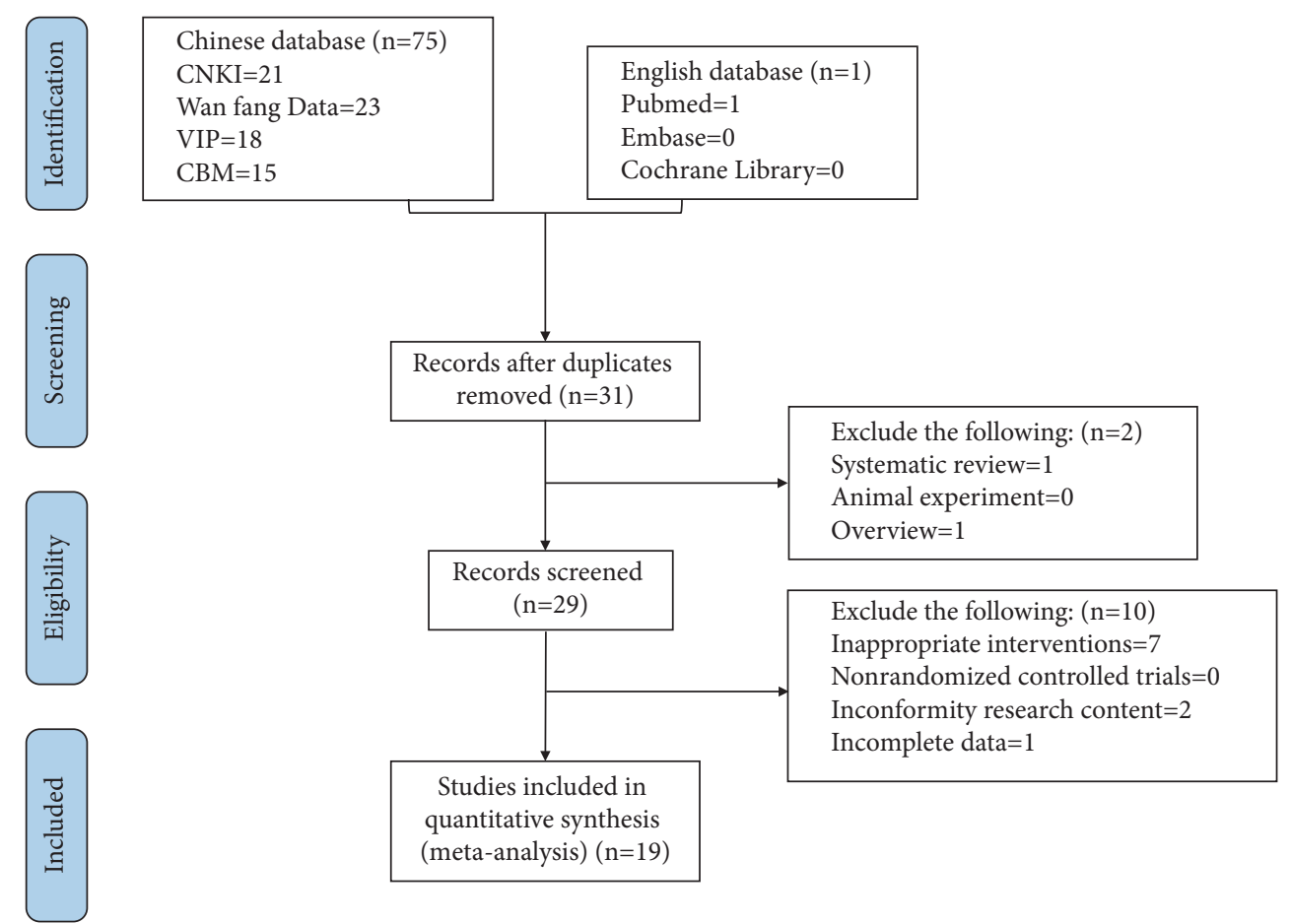

FIGURE 2: Preferred reporting items for systematic reviews and meta-analysis (PRISMA) search diagram.

The funnel plot was used to investigate the presence of publication bias in this study (Figure 5(b)), and Egger's bias test indicated that $P<0.005$ (Figure 5(c)), suggesting that there was a certain publication bias. The funnel plot was processed by the trim and fill method (Figure 5(d)). Therefore, it was necessary to continue to include seven documents whose results were similar to the RCTs $[22,23,26-28,33,39]$. This guaranteed the symmetry of the funnel plot and eliminated the publication bias. In summary, compared with chemotherapy alone, the treatment of firstline platinum-based chemotherapy plus cinobufacini capsule could significantly improve ORR.

3.5.2. Survival Rate. The 1-year survival rate included 8 studies $[24,30,32,33,35,36,38,40]$ with a total of 659 patients, including 338 cases in the experimental group and 321 cases in the control group. Six studies $[23,24,32,35,36,38]$ including 554 patients that reported the 2 -year survival rate were involved. The fixed-effect model combined the trials, 1 -year survival rate $(\mathrm{RR}=1.44,95 \% \mathrm{CI}$ $(1.28,1.63))$, and 2 -year survival rate $(\mathrm{RR}=1.78,95 \% \mathrm{CI}$ $(1.42,2.22))$. Results of the heterogeneity test results indicated that the 1 -year survival rate was $P>0.05, I^{2}=34.7 \%$ and the 2-year survival rate was $P>0.05, I^{2}=0.0 \%$ (Figure 6), suggesting that the heterogeneity was acceptable.

3.5.3. Leukocyte Toxicity. In this study, leukocyte decline was reported in 9 RCTs $[22,24,29,30,33,34,36,38,39]$, involving a total of 739 patients, including 376 cases in the experimental group and 363 cases in the control group. The heterogeneity test $\left(P<0.005, I^{2}=85.8 \%\right.$ (Figure 7 (a) upper part)) suggested that there was significant heterogeneity among the RCTs included in this study. Further investigation of the L'Abbe plot (Figure 7(b)) and Galbraith plot (Figure 7(c)) suggested that some articles had a greater impact on heterogeneity. A sensitivity analysis of the 9 included articles revealed that the result of the study by $\mathrm{Li}$ et al. [36] had a greater impact on heterogeneity (Figure 7(d)). Meta-analysis was performed after removal of the study using fixed-effect model combined trials $(\mathrm{RR}=0.61,95 \% \mathrm{CI}(0.51,0.72))$. The heterogeneity test $\left(P>0.05, I^{2}=24.7 \%\right)$ (Figure $7($ a) lower part) suggested that heterogeneity was within the acceptable range.

3.5.4. Platelet Toxicity. A total of 8 RCTs [22, 24, 28-30, 33, 36, 38] were included: 676 patients, including 343 cases in the experimental group and 333 cases in the control group. The heterogeneity test result was $P<0.005, I^{2}=81.3 \%$ (Figure 8(a) upper part), suggesting that there was significant heterogeneity among the RCTs included in this study. Further investigation of the L'Abbe plot (Figure 8(b)) and Galbraith plot (Figure 8(c)) suggested that some articles had a greater impact on heterogeneity. A sensitivity analysis of the 8 included RCTs revealed [36] a greater impact on heterogeneity (Figure $8(\mathrm{~d})$ ). Meta-analysis was performed after removal of the study using fixed-effect model combined trials $(\mathrm{RR}=0.52,95 \% \mathrm{CI}(0.41,0.67))$; the heterogeneity test revealed $P>0.05, I^{2}=0.0 \%$ (Figure 8 (a) lower part), and heterogeneity was significantly reduced.

3.5.5. Vomiting Toxicity. The outcome included 14 articles [22-26, 28-30, 32-34, 36, 38, 39], a total of 1162 patients, 
TABLE 1: Principal characteristics of the studies included in the meta-analysis.

\begin{tabular}{|c|c|c|c|c|c|c|c|c|c|}
\hline \multirow[b]{2}{*}{$\begin{array}{l}\text { Study } \\
\text { ID }\end{array}$} & \multirow{2}{*}{$\begin{array}{l}\text { Sample } \\
\text { size(T/ } \\
\text { C)/case }\end{array}$} & \multicolumn{2}{|c|}{ Age $($ mean $\pm S D)$} & \multirow[b]{2}{*}{ Stage } & \multicolumn{2}{|c|}{ Intervention } & \multirow{2}{*}{$\begin{array}{c}\text { Cinobufacini } \\
\text { dose }\end{array}$} & \multirow[b]{2}{*}{ Duration(day) } & \multirow[b]{2}{*}{ Outcome } \\
\hline & & Test group & $\begin{array}{c}\text { Control } \\
\text { group }\end{array}$ & & Test group & $\begin{array}{l}\text { Control } \\
\text { group }\end{array}$ & & & \\
\hline $\mathrm{Su}[22]$ & $44 / 44$ & $56.48 \pm 7.05$ & $55.74 \pm 6.12$ & $\begin{array}{l}\text { IIIb, } \\
\text { IV }\end{array}$ & $\mathrm{DP}+$ cinobufacini & $\mathrm{DP}$ & $0.6 \mathrm{~g} \cdot \mathrm{bid} \cdot \mathrm{po}$ & 84 & (1)(4) (5) (6) \\
\hline $\operatorname{Li}[23]$ & $21 / 18$ & -- & -- & $\begin{array}{l}\text { IIIb, } \\
\text { IV }\end{array}$ & $\mathrm{DP}+$ cinobufacini & DP & $0.75 \mathrm{~g} \cdot \mathrm{tid} \cdot \mathrm{po}$ & 90 & (2) \\
\hline $\begin{array}{l}\text { Chen } \\
\text { et al. } \\
{[24]}\end{array}$ & $36 / 31$ & $54.26 \pm 10.38$ & $53.45 \pm 11.69$ & $\begin{array}{l}\text { III, } \\
\text { IV }\end{array}$ & $\mathrm{GP}+$ cinobufacini & GP & $0.5 \mathrm{~g} \cdot \mathrm{tid} \cdot \mathrm{po}$ & 84 & (1) (2) (3) (4) (5) (6) (7) \\
\hline $\operatorname{Li}[25]$ & $38 / 37$ & $60.09 \pm 4.81$ & $58.97 \pm 4.63$ & $\begin{array}{l}\text { III, } \\
\text { IV }\end{array}$ & $\mathrm{DP}+$ cinobufacini & DP & $0.5 \mathrm{~g} \cdot \mathrm{tid} \cdot \mathrm{po}$ & 42 & (1) (6) (7) \\
\hline $\begin{array}{l}\text { Huang } \\
{[26]}\end{array}$ & $43 / 43$ & $61.58 \pm 7.26$ & $61.23 \pm 7.15$ & $\begin{array}{l}\text { IIIb, } \\
\text { IV }\end{array}$ & $\mathrm{GP}+$ cinobufacini & GP & $0.5 \mathrm{~g} \cdot \mathrm{bid} \cdot \mathrm{po}$ & 42 & (1) (6) (7) \\
\hline $\begin{array}{l}\text { Li et al. } \\
{[23]}\end{array}$ & $58 / 58$ & $56.38 \pm 8.24$ & $57.12 \pm 8.44$ & $\begin{array}{l}\text { IIIb, } \\
\text { IV }\end{array}$ & $\mathrm{GP}+$ cinobufacini & GP & $0.5 \mathrm{~g} \cdot \mathrm{bid} \cdot \mathrm{po}$ & 84 & (1) (3) (6) (7) \\
\hline $\begin{array}{l}\text { Lan } \\
\text { et al. } \\
{[27]}\end{array}$ & $43 / 42$ & $55.63 \pm 12.05$ & $56.49 \pm 11.61$ & $\begin{array}{l}\text { III, } \\
\text { IV }\end{array}$ & $\mathrm{TC}+$ cinobufacini & TC & $0.5 \mathrm{~g} \cdot \mathrm{tid} \cdot \mathrm{po}$ & 63 & (1) \\
\hline $\begin{array}{l}\text { Chen } \\
\text { et al. } \\
{[28]}\end{array}$ & $31 / 31$ & $55.87 \pm 6.58$ & $56.29 \pm 6.49$ & $\begin{array}{l}\text { IIIb, } \\
\text { IV }\end{array}$ & $\begin{array}{c}\mathrm{GP} / \\
\mathrm{AP}+\text { cinobufacini }\end{array}$ & GP/AP & $0.5 \mathrm{~g} \cdot \mathrm{tid} \cdot \mathrm{po}$ & 42 & (1) (5) (6) (7) \\
\hline $\begin{array}{l}\text { Yu et al. } \\
\text { [29] }\end{array}$ & $33 / 30$ & -- & -- & $\begin{array}{l}\text { III, } \\
\text { IV }\end{array}$ & $\mathrm{GP}+$ cinobufacini & GP & $0.5 \mathrm{~g} \cdot \mathrm{tid} \cdot \mathrm{po}$ & 42 & (1) (4) (5) (6) \\
\hline Liu [30] & $40 / 40$ & $67.88 \pm 2.27$ & $68.54 \pm 2.11$ & $\begin{array}{l}\text { IIIb, } \\
\text { IV }\end{array}$ & $\begin{array}{c}\mathrm{TP} / \\
\mathrm{NP}+\text { cinobufacini }\end{array}$ & TP/NP & $0.6 \mathrm{~g} \cdot \mathrm{bid} \cdot \mathrm{po}$ & 42 & (2) (4) (5) (6) \\
\hline $\begin{array}{l}\text { Chen } \\
\text { et al. } \\
{[31]}\end{array}$ & $36 / 36$ & $56.90 \pm 11.00$ & $56.20 \pm 10.70$ & $\begin{array}{l}\text { IIIb, } \\
\text { IV }\end{array}$ & $\mathrm{TC}+$ cinobufacini & TC & $0.5 \mathrm{~g} \cdot \mathrm{tid} \cdot \mathrm{po}$ & 84 & (1) (7) \\
\hline $\begin{array}{l}\text { Pu et al. } \\
{[32]}\end{array}$ & $42 / 38$ & $54.60 \pm 9.38$ & $57.83 \pm 12.42$ & $\begin{array}{l}\text { III, } \\
\text { IV }\end{array}$ & $\mathrm{GP}+$ cinobufacini & GP & $0.5 \mathrm{~g} \cdot \mathrm{bid} \cdot \mathrm{po}$ & 42 & (1) (2) (3) (6) (7) \\
\hline Shi [33] & $51 / 51$ & -- & -- & $\begin{array}{l}\text { III, } \\
\text { IV }\end{array}$ & $\mathrm{TP}+$ cinobufacini & $\mathrm{TP}$ & $0.6 \mathrm{~g} \cdot \mathrm{tid} \cdot \mathrm{po}$ & 42 & (1) (2) (4) (5) (6) \\
\hline $\begin{array}{l}\text { Wei } \\
\text { and Xu } \\
{[34]}\end{array}$ & $34 / 34$ & $57.39 \pm 4.31$ & $58.31 \pm 2.57$ & $\begin{array}{l}\text { III, } \\
\text { IV }\end{array}$ & $\mathrm{GP}+$ cinobufacini & GP & $0.5 \mathrm{~g} \cdot \mathrm{tid} \cdot \mathrm{po}$ & 42 & (1)(4) (6) \\
\hline $\begin{array}{l}\text { Chen } \\
\text { et al. } \\
{[35]}\end{array}$ & $40 / 40$ & $59.30 \pm 7.90$ & $59.50 \pm 7.50$ & $\begin{array}{l}\text { IIIb, } \\
\text { IV }\end{array}$ & $\mathrm{GP}+$ cinobufacini & GP & $0.6 \mathrm{~g} \cdot \mathrm{tid} \cdot \mathrm{po}$ & 42 & (1) (2) (3) \\
\hline $\begin{array}{l}\text { Li et al. } \\
{[36]}\end{array}$ & $63 / 63$ & $58.73 \pm 9.54$ & $57.96 \pm 9.86$ & $\begin{array}{l}\text { IIIb, } \\
\text { IV }\end{array}$ & $\mathrm{DP}+$ cinobufacini & DP & $0.5 \mathrm{~g} \cdot \mathrm{tid} \cdot \mathrm{po}$ & 105 & (1) (2) (3) (4) (5) (6) \\
\hline $\begin{array}{l}\text { Xiao } \\
\text { et al. } \\
{[37]}\end{array}$ & $68 / 62$ & -- & -- & IV & $\mathrm{GP}+$ cinobufacini & GP & $0.5 \mathrm{~g} \cdot \mathrm{tid} \cdot \mathrm{po}$ & 42 & (1) \\
\hline Liu [38] & $45 / 40$ & - - & -- & $\begin{array}{l}\text { III, } \\
\text { IV }\end{array}$ & $\begin{array}{c}\mathrm{NP} / \\
\mathrm{TP}+\text { cinobufacini }\end{array}$ & NP/TP & $0.5 \mathrm{~g} \cdot \mathrm{bid} \cdot \mathrm{po}$ & 42 & (1) (2) (3) (4) (5) (6) \\
\hline $\begin{array}{l}\text { Miao } \\
\text { et al. } \\
{[39]}\end{array}$ & $30 / 30$ & $58.00 \pm 7.00$ & $57.00 \pm 6.50$ & $\begin{array}{l}\text { IIIb, } \\
\text { IV }\end{array}$ & $\mathrm{TP}+$ cinobufacini & $\mathrm{TP}$ & $0.5 \mathrm{~g} \cdot \mathrm{tid} \cdot \mathrm{po}$ & 84 & (1)(4) (6) \\
\hline
\end{tabular}

Note. (1) $\mathrm{T}$ is the test group; C is the control group; AP: pemetrexed + cisplatin; DP: docetaxel + cisplatin; GP: gemcitabine + cisplatin; NP: vinorelbine + cisplatin; TC: paclitaxel + carboplatin; TP: paclitaxel + cisplatin; (2) outcome index: (1) ORR; (2) one-year survival rate; (3) two-year survival rate; (4) leukocyte toxicity; (5) platelet toxicity; (6) vomiting reaction; (7) immune response.

including 588 cases in the experimental group and 574 cases in the control group. The heterogeneity was $P<0.005$ and $I^{2}=71.5 \%$ (Figure $9(\mathrm{a})$ ), suggesting that there was strong heterogeneity among the included literatures in this study. According to Figure 9(a) and Table 1, it was highly suspected that heterogeneity resulted from different intervention measures. The results of the meta-regression analysis of 14 literatures with the ' $\log R R^{\prime}$ as the dependent variable and 'intervention' as the independent variable are shown in Figures 9(b) and 9(c), suggesting the independent variable 'intervention' could significantly affect the trials. Based on this conclusion, a subgroup study was conducted (Figure 9(d)). The result of the heterogeneity test for the subgroup (others + cinobufacini) was $P>0.05, I^{2}=31.7 \%$, fixed-effect model combined trials ( $\mathrm{RR}=0.59,95 \% \mathrm{CI}(0.50$, $0.69)$ ), and the weight was $62.77 \%$. The result of 


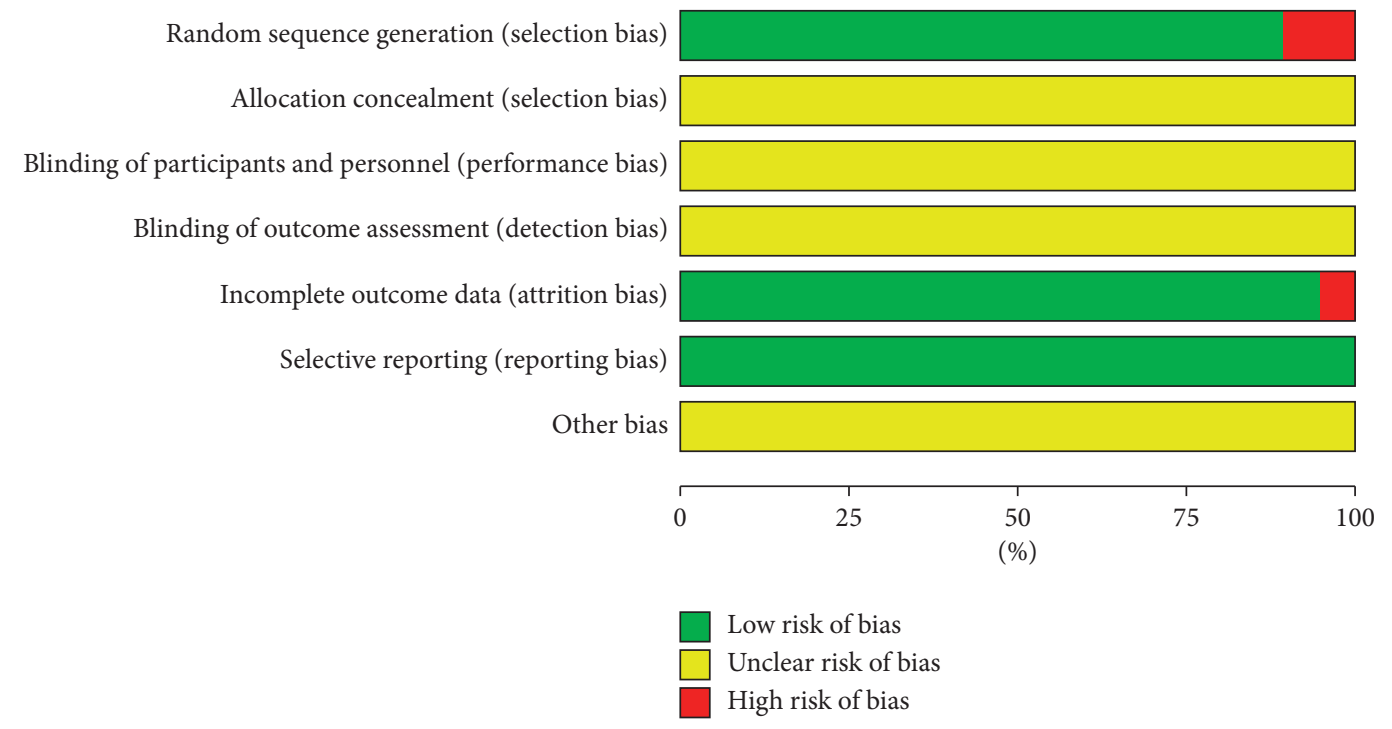

FIgURE 3: Risk of bias graph.

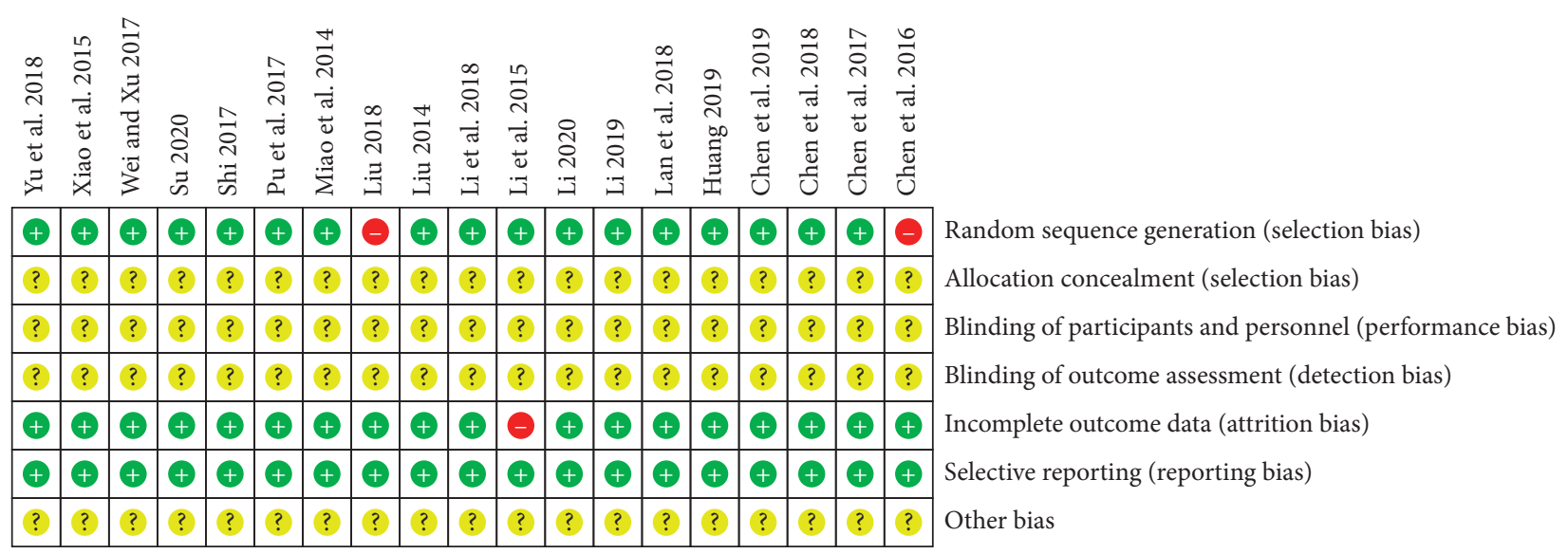

FIGURE 4: Risk of bias summary.

heterogeneity test for the subgroup (GP + cinobufacini) showed that $P>0.05, I^{2}=0.0 \%$, the fixed-effect model was used to combine trials $(\mathrm{RR}=1.12,95 \% \mathrm{CI}(0.96,1.32))$, and the weight was $37.23 \%$. In summary, vomiting toxicity was aggravated with GP chemotherapy, while it reduced with other chemotherapy regimens.

\subsubsection{Immune Response}

(1). $C D 3^{+}$T Cells. A total of 558 patients were included in this study, including 284 cases in the experimental group and 274 cases in the control group. The heterogeneity among the 7 articles $[23-26,28,31,32]$ included in this study was examined by a forest plot $\left(P<0.005, I^{2}=72.2 \%\right.$; Figure 10(a) upper part), and obvious heterogeneity was noted. Sensitivity analysis was performed on seven articles (Figure 10(b)), and it was highly suspected that heterogeneity was generated by the article by Li et al. [23]. After removing this article, heterogeneity was $P>0.05$ and $I^{2}=0.0 \%$ (Figure 10 (a) lower part) and significantly reduced. The fixed-effect model combined trials $(\mathrm{SMD}=1.25,95 \% \mathrm{CI}(1.05,1.45))$. In summary, the experimental group can significantly improve the level of $\mathrm{CD}^{+}$.

(2). $C D 4^{+} T$ Cells. A total of 558 patients were included in the outcome, including 284 cases in the experimental group and 274 cases in the control group. The heterogeneity among the 7 RCTs [23-26, 28, 31, 32] included in this study was $P<0.05, I^{2}=60.8 \%$ (Figure $11(\mathrm{a})$ ), and there was obvious heterogeneity. It was highly suspected that heterogeneity was caused by the difference in the time of administration in the meta-regression analysis of 14 literatures with the 'SMD' as the dependent variable and 'duration' as the independent variable; the results are shown in Figures 11(b) and (c). For $P<0.05$, the independent variable 'duration' could significantly affect the trials. The result of the heterogeneity test for the subgroup (84 days) was $P>0.05, I^{2}=13.6 \%$, the fixed- 


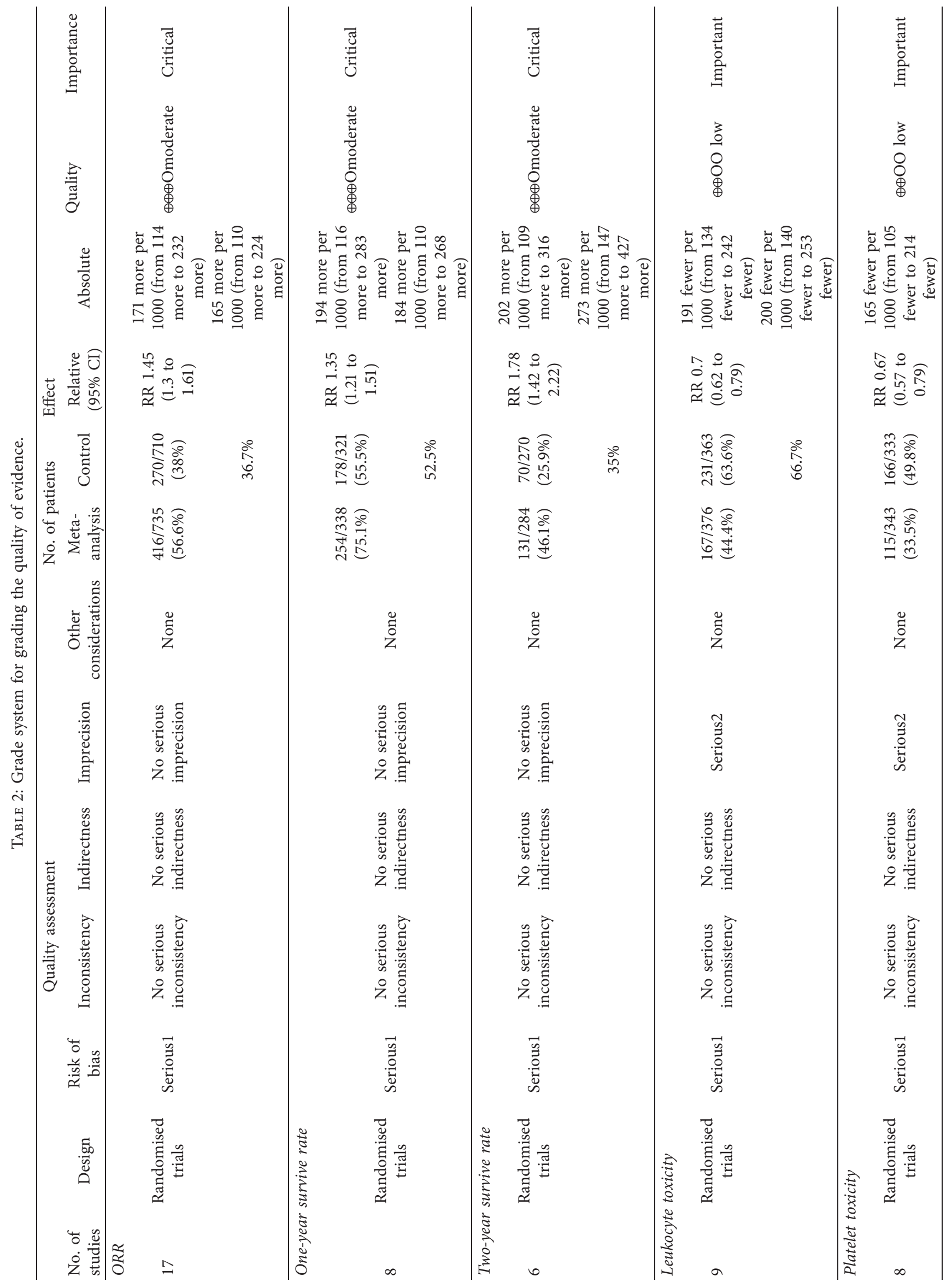




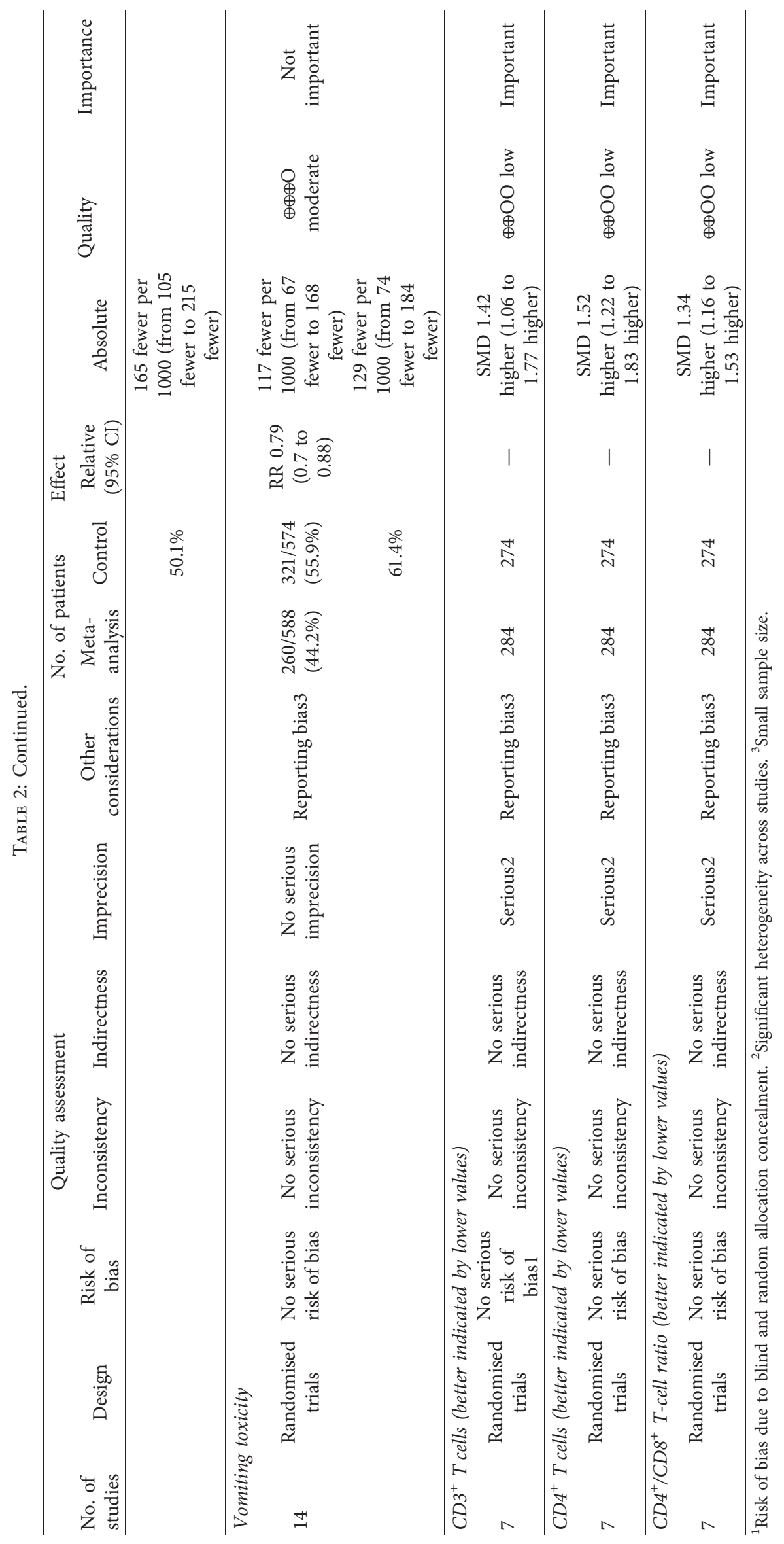


TABle 3: Principal characteristics of the studies included in the meta-analysis.

\begin{tabular}{|c|c|c|c|c|c|c|c|}
\hline \multicolumn{2}{|c|}{ Outcome or subgroup } & $\begin{array}{l}\text { No. of } \\
\text { Studies }\end{array}$ & Participants & $\begin{array}{l}\text { Statistical } \\
\text { method }\end{array}$ & Effect size & Heterogeneity & $\begin{array}{c}\text { Publication } \\
\text { bias } \\
\text { (Egger's test) }\end{array}$ \\
\hline \multicolumn{2}{|l|}{ ORR } & 17 & 1445 & RR (fixed), 95\% CI & $\begin{array}{c}1.49 \\
{[1.33,1.66]}\end{array}$ & $P=0.994, I^{2}=0.0 \%$ & $P=0.001$ \\
\hline \multicolumn{2}{|c|}{ One-year survival rate } & 8 & 659 & RR (fixed), 95\% CI & $\begin{array}{c}1.44 \\
{[1.28,1.63]}\end{array}$ & $P=0.151, I^{2}=34.7 \%$ & $P=0.088$ \\
\hline \multicolumn{2}{|c|}{ Two-year survival rate } & 6 & 554 & RR (fixed), 95\% CI & $\begin{array}{l}1.78[1.42 \\
2.22]\end{array}$ & $P=0.573, I^{2}=0.0 \%$ & $P=0.018$ \\
\hline \multicolumn{2}{|c|}{ Leukocyte toxicity } & 9 & 739 & RR (fixed), 95\% CI & $\begin{array}{l}0.61[0.51 \\
0.72]\end{array}$ & $P=0.232, I^{2}=24.7 \%$ & $P=0.172$ \\
\hline \multicolumn{2}{|l|}{ Platelet toxicity } & 8 & 676 & RR (fixed), 95\% CI & $\begin{array}{l}0.52[0.41 \\
0.67]\end{array}$ & $P=0.433, I^{2}=0.0 \%$ & $P=0.708$ \\
\hline $\begin{array}{l}\text { Vomiting } \\
\text { response }\end{array}$ & Others + cinobufacini & 8 & 678 & RR (fixed), 95\% CI & $\begin{array}{l}0.59[0.50 \\
0.69]\end{array}$ & $P=0.175, I^{2}=31.7 \%$ & $P=0.614$ \\
\hline \multicolumn{2}{|l|}{$\mathrm{GP}+$ cinobufacini } & 6 & 484 & RR (fixed), 95\% CI & $\begin{array}{l}1.12[0.96 \\
1.32]\end{array}$ & $P=0.466, I^{2}=0.0 \%$ & $P=0.811$ \\
\hline \multicolumn{2}{|l|}{$\mathrm{CD}^{+}$level } & 7 & 558 & $\begin{array}{l}\text { SMD (fixed), } 95 \% \\
\text { CI }\end{array}$ & $\begin{array}{l}1.25[1.05 \\
1.45]\end{array}$ & $P=0.874, I^{2}=0.0 \%$ & $P=0.883$ \\
\hline \multirow[t]{2}{*}{$\mathrm{CD} 4^{+}$level } & 84 days & 3 & 255 & $\begin{array}{l}\text { SMD (fixed), } 95 \% \\
\text { CI }\end{array}$ & $\begin{array}{l}1.88[1.58, \\
2.18]\end{array}$ & $P=0.314, I^{2}=13.6 \%$ & $P=0.765$ \\
\hline & 42 days & 4 & 303 & $\begin{array}{l}\text { SMD (fixed), } 95 \% \\
\text { CI }\end{array}$ & $\begin{array}{l}1.27[1.02 \\
1.51]\end{array}$ & $P=0.352, I^{2}=8.1 \%$ & $P=0.196$ \\
\hline \multirow[t]{2}{*}{$\begin{array}{l}\mathrm{CD}^{+} / \\
\mathrm{CD}^{+}{ }^{+} \text {level }\end{array}$} & $0.5 \mathrm{~g} \cdot \mathrm{tid} \cdot \mathrm{po}$ & 4 & 276 & $\begin{array}{l}\text { SMD (fixed), } 95 \% \\
\text { CI }\end{array}$ & $\begin{array}{c}1.01[0.76 \\
1.26]\end{array}$ & $P=0.139, I^{2}=45.4 \%$ & $P=0.634$ \\
\hline & $0.5 \mathrm{~g} \cdot \mathrm{bid} \cdot \mathrm{po}$ & 3 & 282 & $\begin{array}{l}\text { SMD (fixed), } 95 \% \\
\text { CI }\end{array}$ & $\begin{array}{l}1.78[1.50 \\
2.06]\end{array}$ & $P=0.842, I^{2}=0.0 \%$ & $P=0.661$ \\
\hline
\end{tabular}

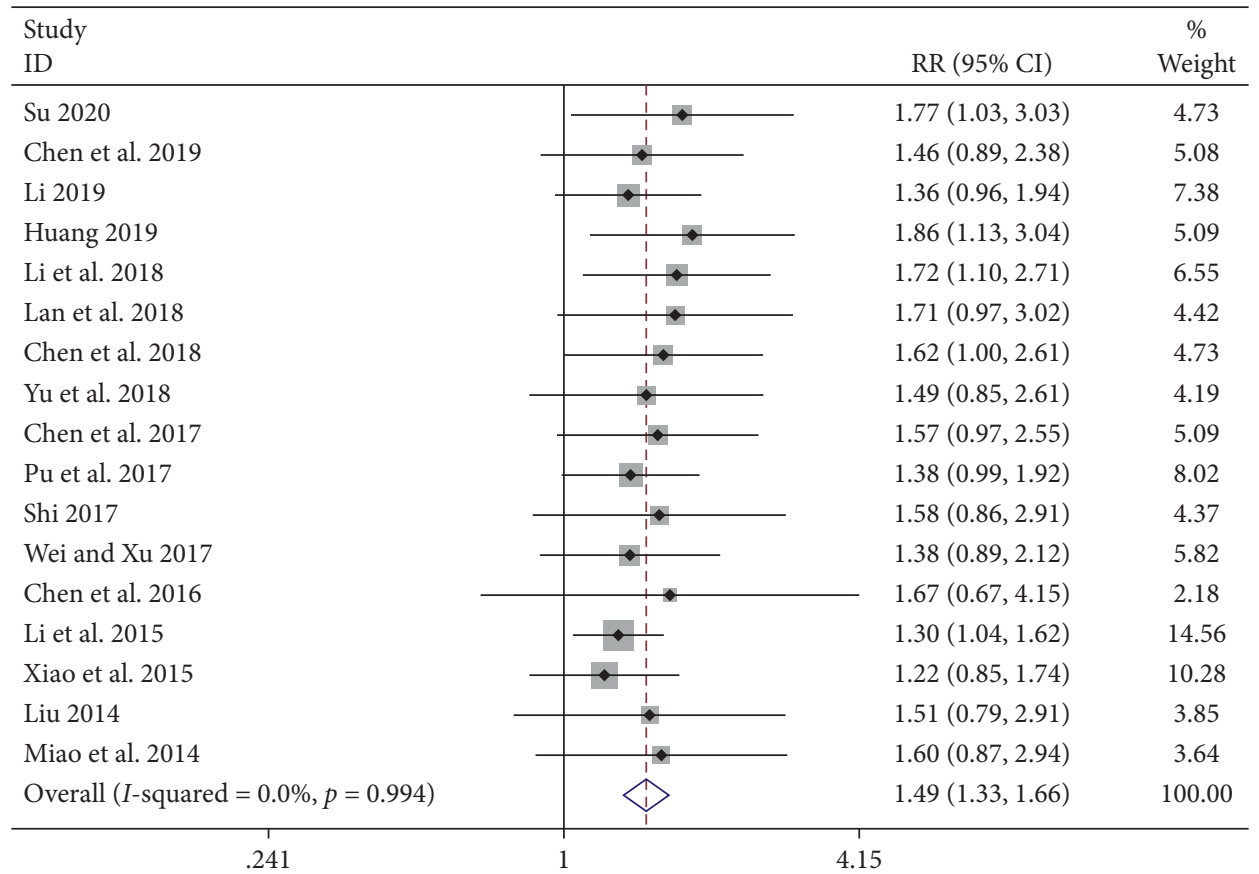

(a)

FIgURE 5: Continued. 


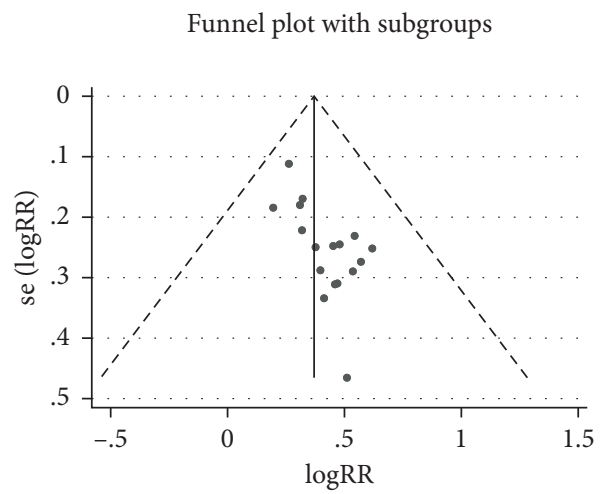

(b)

\begin{tabular}{ccccccc}
\hline Std_Eff & Coef. & Std. Err. & $\mathrm{t}$ & $\mathrm{P}>|\mathrm{t}|$ & \multicolumn{2}{c}{ [95\% Conf. Interval] } \\
\hline slope & 0.1200216 & 0.0655947 & 1.83 & 0.087 & -0.0197902 & 0.2598334 \\
bias & 1.203169 & 0.2979629 & 4.04 & 0.001 & 0.5680764 & 1.838262 \\
\hline
\end{tabular}

(c)

Filled funnel plot with pseudo 95\% confidence limits

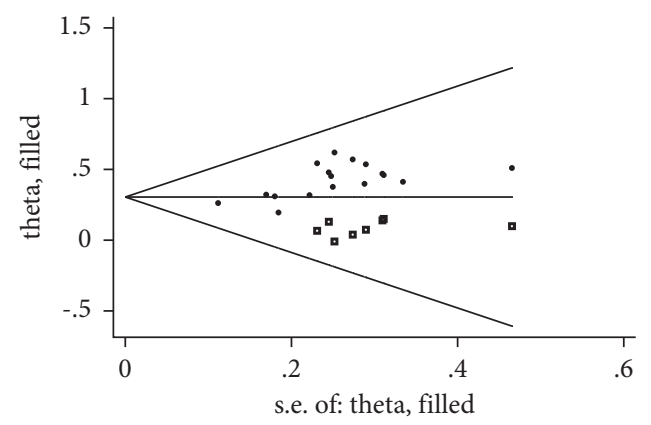

(d)

FIGURE 5: Meta-analysis showing a significant improvement in the ORR in the experimental group compared with that of the control group. (a) Meta-analysis of ORR in included studies. (b) Funnel plots for publication biases of ORR in included studies. (c) Results of Egger's bias test. (d) The impact of publication bias on results by the trim and fill method.

effect model combined trials $(\mathrm{SMD}=1.88,95 \%$ CI $(1.58$, $2.18)$ ), and the weight was $41.12 \%$. The result of the heterogeneity test for the subgroup ( 42 days) indicated $P>0.05$, $I^{2}=8.1 \%$; the fixed-effect model was used to combine trials $(\mathrm{SMD}=1.27,95 \% \mathrm{CI}(1.02,1.51))$, and the weight was $58.88 \%$ (Figure $11(\mathrm{~d})$ ). In summary, the experimental group could significantly improve the $\mathrm{CD} 4^{+}$level, and 84 days was more effective than 42 days.

(3). $C D 4^{+} / C D 8^{+} T$-Cell Ratio. A total of 558 patients were included in the outcome, including 284 cases in the experimental group and 274 cases in the control group. The heterogeneity among the 7 RCTs [23-26, 28, 31, 32] included in this study was $P<0.005, I^{2}=72.9 \%$ (Figure $12(\mathrm{a})$ ), and there was obvious heterogeneity. We highly suspected that heterogeneity was caused by the difference in the administration dose; then, the 'SMD' as the dependent variable dose was an independent variable for meta-regression analysis of 7 RCTs. The results are shown in Figures 12(b) and 12 (c). For $P<0.05$, the independent variable 'administered dose' could significantly affect the "SMD." A subgroup study was performed (Figure 12(d)). The result of the heterogeneity test for the subgroup ( $0.5 \mathrm{~g} \cdot \mathrm{tid} \cdot \mathrm{po})$ was $P>0.05, I^{2}=45.4 \%$, the fixed-effect model combined trials $(\mathrm{SMD}=1.01,95 \% \mathrm{CI}(0.76,1.26))$, and the weight was $54.6 \%$; The result of the heterogeneity test for the subgroup (0.5 g.bid.po) indicated $P>0.05, I^{2}=0.0$, the fixed-effect model was used to combine trials (SMD $=1.78,95 \% \mathrm{CI}(1.50$, $2.06)$ ), and the weight was $45.4 \%$. In summary, the experimental group could significantly increase the $\mathrm{CD} 4^{+} / \mathrm{CD}^{+}$ ratio, and $0.5 \mathrm{~g} \cdot$ bid.po was more obvious.

\section{Discussion}

A total of 19 clinical RCTs with 1,564 individuals suffering from advanced NSCLC were selected in this meta-analysis. The main results demonstrated that combining firstline platinum-based chemotherapy with cinobufacini capsule in the treatment of NSCLC may increase survival rate, ORR, and immunity and reduce the toxicity of chemotherapy when compared with the chemotherapy alone. 


\begin{tabular}{|c|c|c|c|}
\hline $\begin{array}{l}\text { Study } \\
\text { ID }\end{array}$ & & RR $(95 \%$ CI $)$ & $\begin{array}{c}\% \\
\text { Weight }\end{array}$ \\
\hline \multicolumn{4}{|l|}{ One year survival rate } \\
\hline Li 2020 & $\rightarrow$ & $1.29(0.68,2.43)$ & 5.03 \\
\hline Chen et al. 2019 & $\rightarrow$ & $1.59(0.99,2.55)$ & 8.15 \\
\hline Liu 2018 & $\longrightarrow$ & $1.63(1.13,2.35)$ & 11.09 \\
\hline Pu et al. 2017 & $\rightarrow$ & $1.13(0.90,1.43)$ & 17.16 \\
\hline Shi 2017 & $\rightarrow-$ & $1.21(0.95,1.53)$ & 19.84 \\
\hline Chen et al. 2016 & $\longrightarrow$ & $1.43(1.06,1.94)$ & 13.42 \\
\hline Li et al. 2015 & $\longrightarrow$ & $2.16(1.42,3.27)$ & 11.09 \\
\hline Liu 2014 & $\longrightarrow$ & $1.43(1.06,1.93)$ & 14.21 \\
\hline Subtotal $(\mathrm{I}$-squared $=34.7 \%, \mathrm{p}=0.151)$ & $\diamond$ & $1.44(1.28,1.63)$ & 100.00 \\
\hline \multicolumn{4}{|l|}{ Two year survival rate } \\
\hline Chen et al. 2019 & & $3.16(0.97,10.30)$ & 4.49 \\
\hline Li et al. 2018 & $\longrightarrow$ & $1.67(1.12,2.49)$ & 29.25 \\
\hline Pu et al. 2017 & $\rightarrow$ & $1.39(0.86,2.24)$ & 21.94 \\
\hline Chen et al. 2016 & $\longrightarrow$ & $1.71(1.05,2.80)$ & 19.50 \\
\hline Li et al. 2015 & & $4.00(1.19,13.49)$ & 4.18 \\
\hline Liu 2014 & $\rightarrow$ & $1.65(1.01,2.70)$ & 20.65 \\
\hline Subtotal $(\mathrm{I}$-squared $=0.0 \%, \mathrm{p}=0.573)$ & $\diamond$ & $1.78(1.42,2.22)$ & 100.00 \\
\hline .0741 & 1 & 3.5 & \\
\hline
\end{tabular}

FIGURE 6: Meta-analysis showing a significant improvement in the survival rate in the experimental group compared with that of the control group.

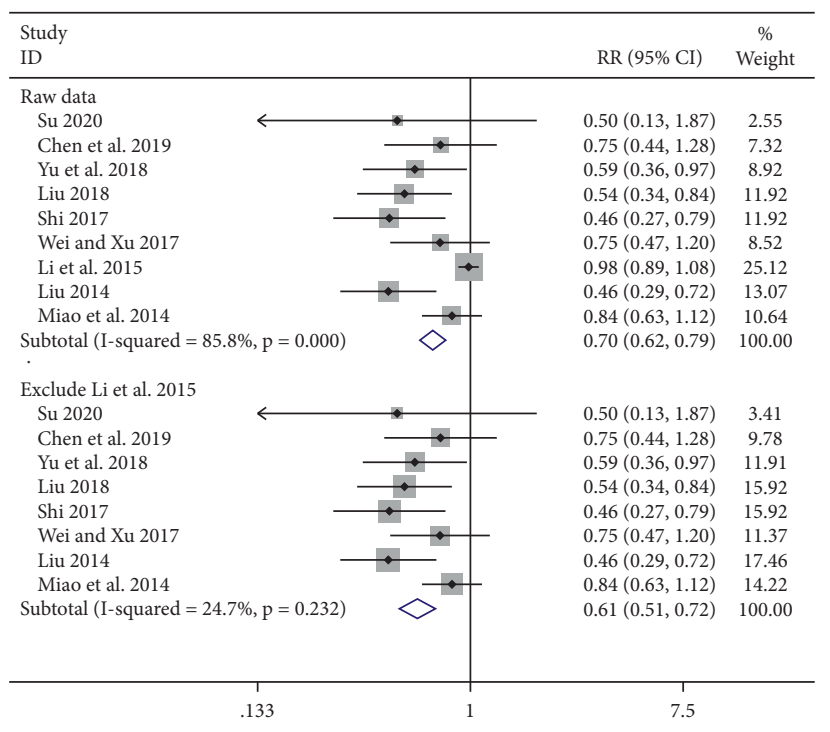

(a)

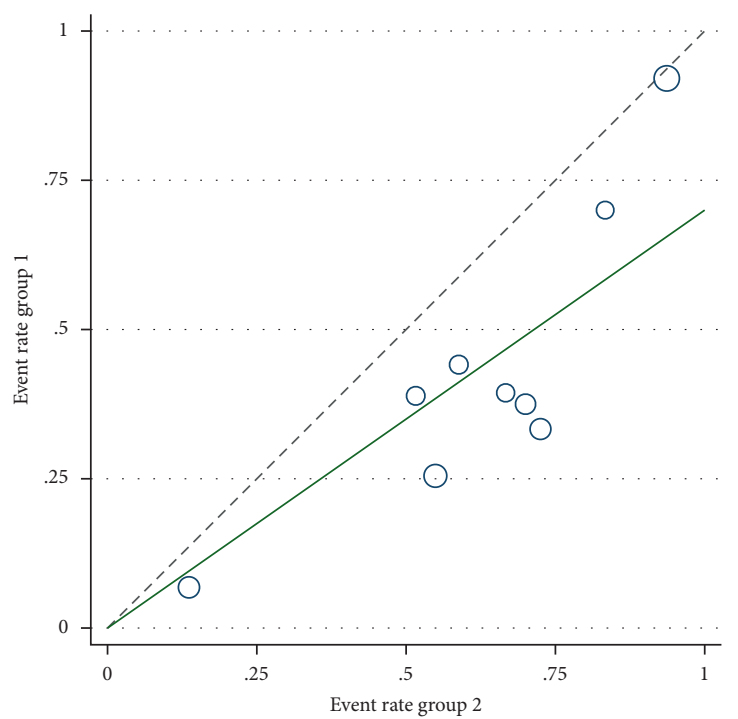

(b)

Figure 7: Continued. 


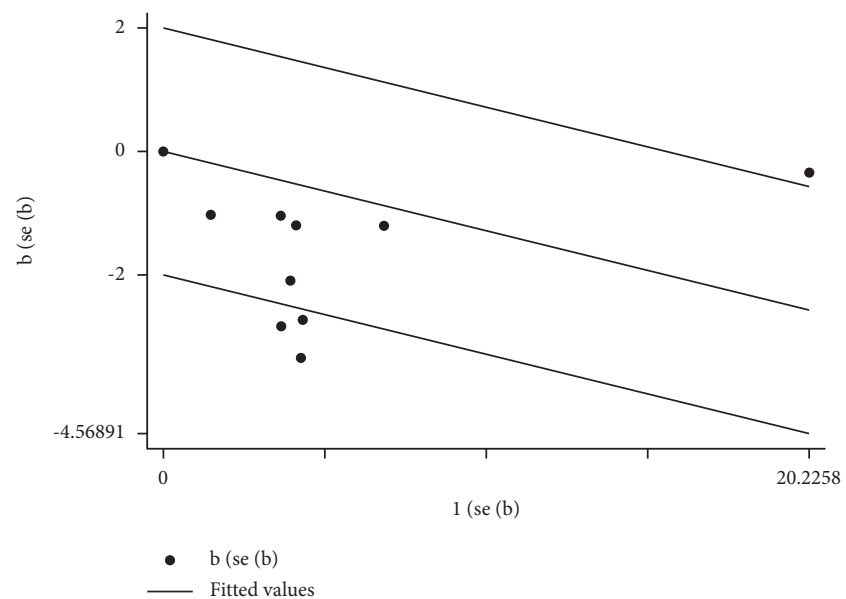

(c)

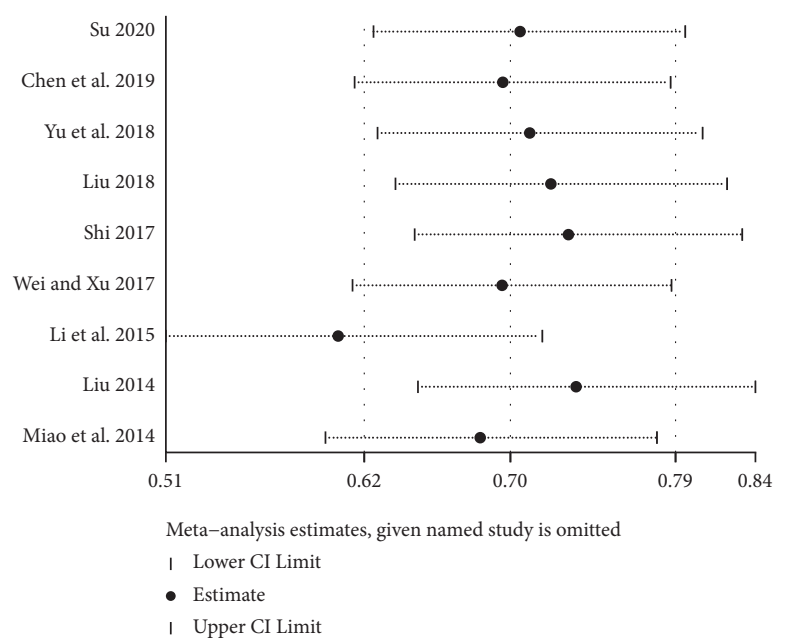

(d)

Figure 7: Meta-analysis showing a significant reduction in the leukocyte toxicity in the experimental group compared with that of the control group. (a) Meta-analysis of leukocyte toxicity in included studies. (b, c) The impact of the literature on heterogeneity by the L'Abbe plot and Galbraith plot. (d) The sensitivity analysis of the nine included articles.

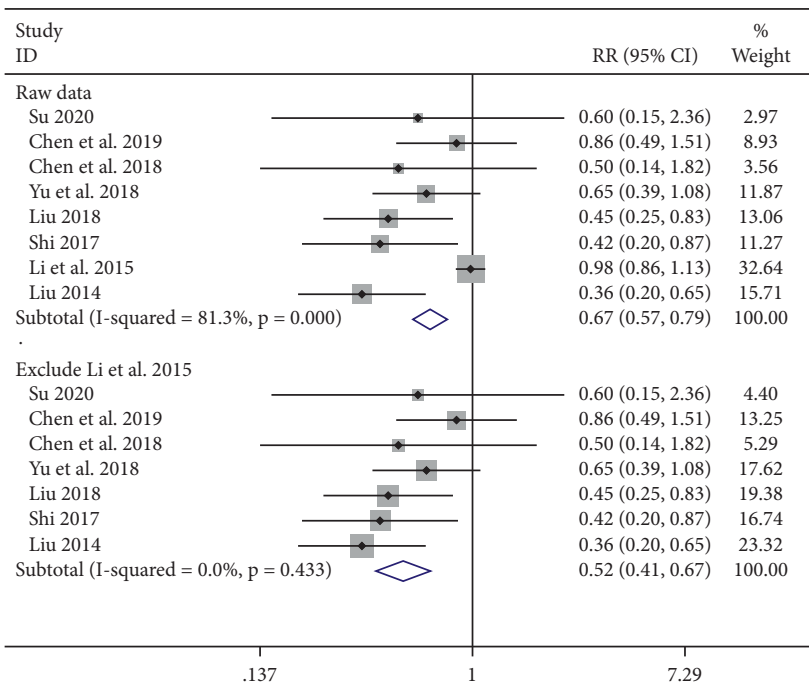

(a)

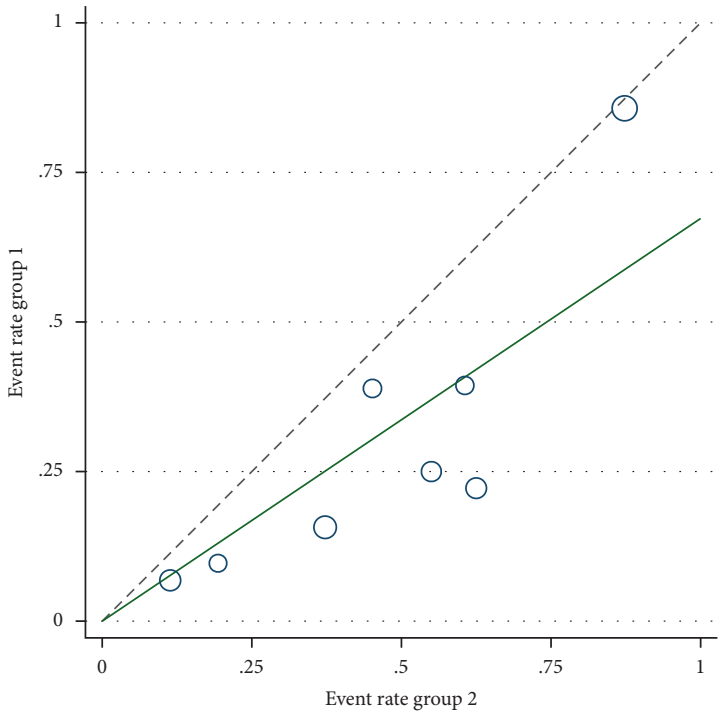

(b)

Figure 8: Continued. 


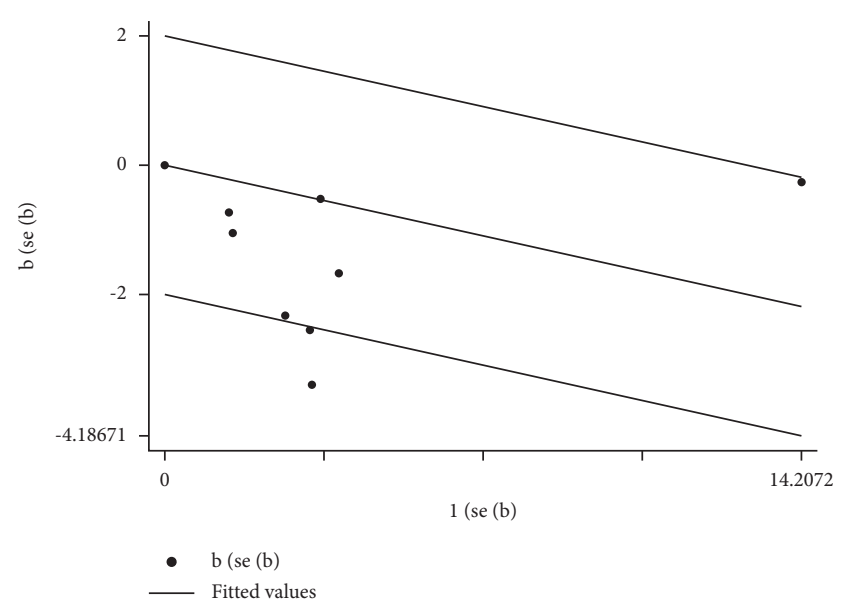

(c)

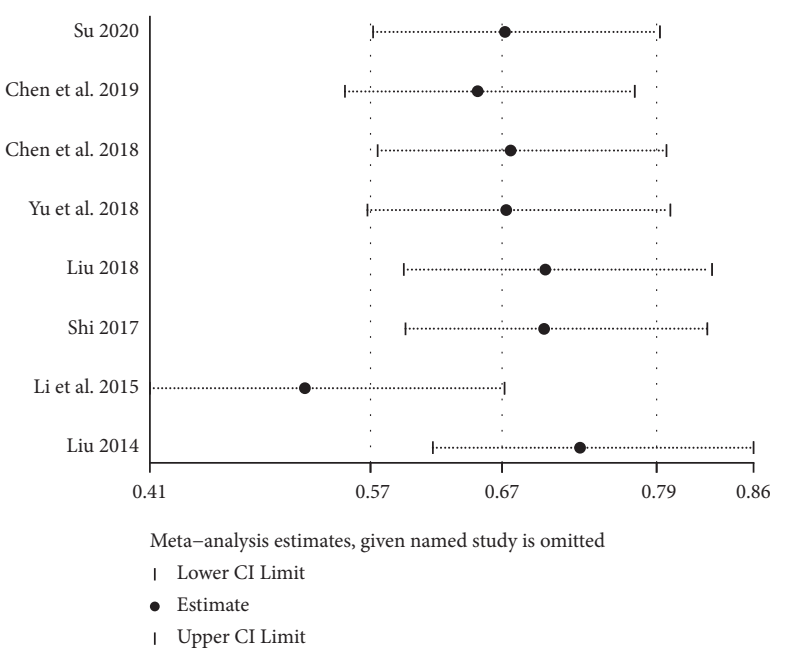

(d)

FIGURE 8: Meta-analysis showing a significant reduction in the platelet toxicity in the experimental group compared with that of the control group. (a) Meta-analysis of platelet toxicity in included studies. (b, c) The impact of the literature on heterogeneity by the L'Abbe plot and Galbraith plot. (d) The sensitivity analysis of the eight included articles.

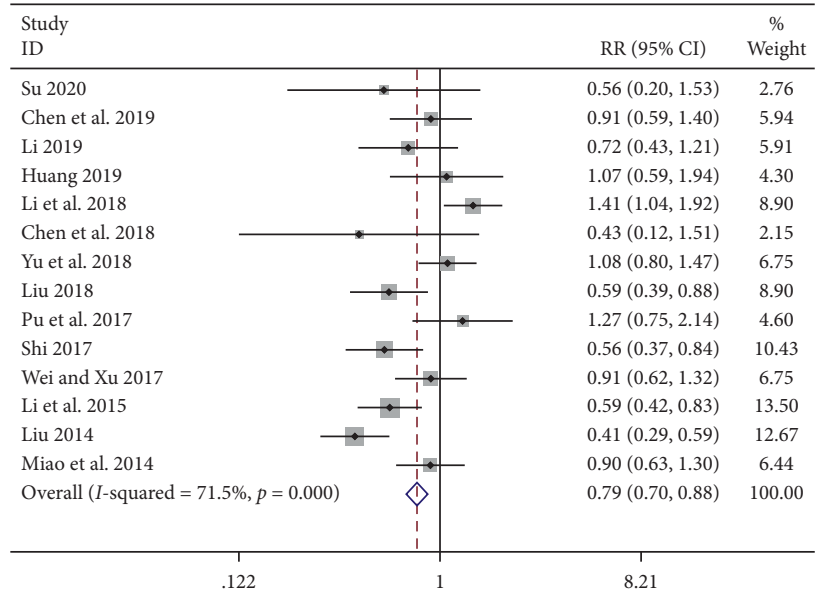

(a)

\begin{tabular}{rcccccc}
\hline $\operatorname{logRR}$ & Coef. & Std. Err. & $\mathrm{t}$ & $\mathrm{P}>|\mathrm{t}|$ & \multicolumn{2}{c}{$[95 \%$ Conf. Interval] } \\
\hline intervention & 0.6130161 & 0.1399528 & 4.38 & 0.001 & 0.3080851 & 0.9179472 \\
_cons & -0.513296 & 0.0968837 & -5.30 & 0.000 & -0.7243874 & -0.3022046 \\
\hline
\end{tabular}

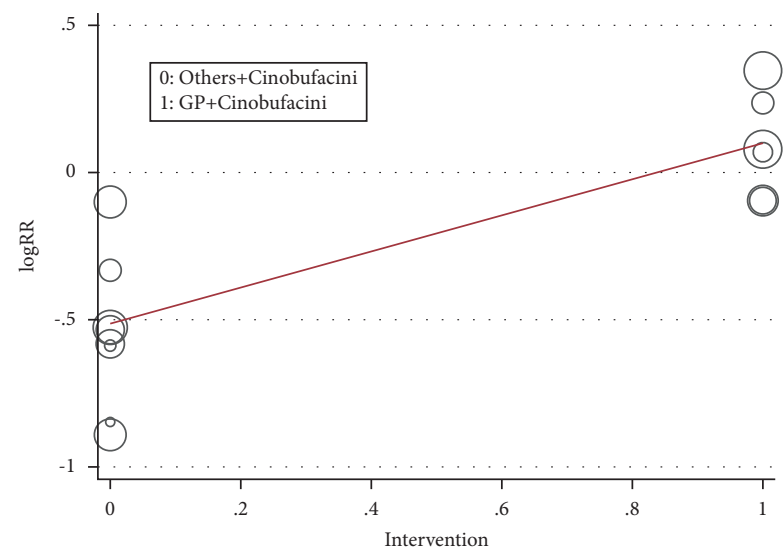

(b)

\begin{tabular}{|c|c|c|}
\hline $\begin{array}{l}\text { Study } \\
\text { ID }\end{array}$ & RR $(95 \%$ CI $)$ & $\begin{array}{c}\% \\
\text { Weight }\end{array}$ \\
\hline Subgroup (Others+Cinobufacini) & & \\
\hline Su 2020 & $0.56(0.20,1.53)$ & 2.76 \\
\hline Li 2019 & $0.72(0.43,1.21)$ & 5.91 \\
\hline Chen et al. 2018 & $0.43(0.12,1.51)$ & 2.15 \\
\hline Liu 2018 & $0.59(0.39,0.88)$ & 8.90 \\
\hline$\ldots 1$ & $0.56(0.37,0.84)$ & 10.43 \\
\hline Li et al. 2015 & $0.59(0.42,0.83)$ & 13.50 \\
\hline$\longrightarrow \quad 1$ & $0.41(0.29,0.59)$ & 12.67 \\
\hline Miao et al. 2014 & $0.90(0.63,1.30)$ & 6.44 \\
\hline Subtotal $(\mathrm{I}$-squared $=31.7 \%, \mathrm{p}=0.175)$ & $0.59(0.50,0.69)$ & 62.77 \\
\hline Subgroup (GP+Cinobufacini) & & \\
\hline Chen et al. 2019 & $0.91(0.59,1.40)$ & 5.94 \\
\hline Huang 2019 & $1.07(0.59,1.94)$ & 4.30 \\
\hline Li et al. 2018 & $1.41(1.04,1.92)$ & 8.90 \\
\hline Yu et al. 2018 & $1.08(0.80,1.47)$ & 6.75 \\
\hline Pu et al. 2017 & $1.27(0.75,2.14)$ & 4.60 \\
\hline Wei and Xu 2017 & $0.91(0.62,1.32)$ & 6.75 \\
\hline Subtotal $(\mathrm{I}$-squared $=0.0 \%, \mathrm{p}=0.466)$ & $1.12(0.96,1.32)$ & 37.23 \\
\hline Overall $(\mathrm{I}$-squared $=71.5 \%, \mathrm{p}=0.000)$ & $0.79(0.70,0.88)$ & 100.00 \\
\hline
\end{tabular}

(d)

FIGURE 9: (a) Meta-analysis of vomiting response in included studies. (b, c) The results of the meta-regression analysis. (d) The subgroup study of vomiting toxicity. 


\begin{tabular}{|c|c|c|c|}
\hline $\begin{array}{l}\text { Study } \\
\text { ID }\end{array}$ & & $\operatorname{SMD}(95 \% \mathrm{CI})$ & $\begin{array}{c}\% \\
\text { Weight }\end{array}$ \\
\hline \multicolumn{4}{|l|}{ Raw data } \\
\hline Chen et al. 2019 & $\rightarrow 1$ & $1.02(0.51,1.53)$ & 7.35 \\
\hline Li 2019 & $\longrightarrow$ & $1.42(0.91,1.93)$ & 7.44 \\
\hline Huang 2019 & $\longrightarrow$ & $1.16(0.70,1.61)$ & 9.18 \\
\hline Li et al. 2018 & $\longrightarrow$ & $2.44(1.96,2.92)$ & 8.26 \\
\hline Chen et al. 2018 & $\longrightarrow$ & $1.44(0.88,2.00)$ & 6.12 \\
\hline Chen et al. 2017 & 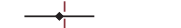 & $1.27(0.76,1.78)$ & 7.45 \\
\hline Pu et al. 2017 & $\rightarrow$ & $1.24(0.76,1.72)$ & 8.33 \\
\hline Subtotal $(\mathrm{I}$-squared $=72.2 \%, \mathrm{p}=0.001)$ & $\phi$ & $1.43(1.24,1.62)$ & 54.13 \\
\hline \multicolumn{4}{|l|}{ Exclude Li et al. 2018} \\
\hline Chen et al. 2019 & $\rightarrow$ & $1.02(0.51,1.53)$ & 7.35 \\
\hline Li 2019 & $\longrightarrow$ & $1.42(0.91,1.93)$ & 7.44 \\
\hline Huang 2019 & $\longrightarrow .1$ & $1.16(0.70,1.61)$ & 9.18 \\
\hline Chen et al. 2018 & $\longrightarrow$ & $1.44(0.88,2.00)$ & 6.12 \\
\hline Chen et al. 2017 & $\stackrel{1}{\square}$ & $1.27(0.76,1.78)$ & 7.45 \\
\hline Pu et al. 2017 & $\longrightarrow$ & $1.24(0.76,1.72)$ & 8.33 \\
\hline Subtotal $(\mathrm{I}$-squared $=0.0 \%, \mathrm{p}=0.874)$ & $\Delta$ & $1.25(1.05,1.45)$ & 45.87 \\
\hline \multirow{2}{*}{$\begin{array}{l}\text { Heterogeneity between groups: } \mathrm{p}=0.201 \\
\text { Overall (I-squared }=52.1 \%, \mathrm{p}=0.015 \text { ) }\end{array}$} & i & & \\
\hline & $\Delta$ & $1.35(1.21,1.49)$ & 100.00 \\
\hline & & & \\
\hline-2.92 & 2.9 & & \\
\hline
\end{tabular}

(a)

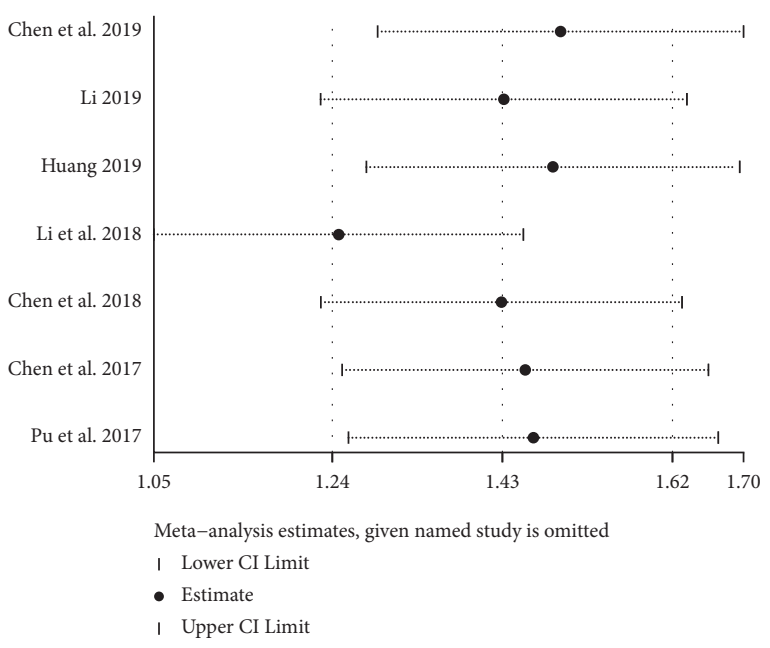

(b)

FIGURE 10: Meta-analysis showing a significant improvement in the $\mathrm{CD}^{+}$level in the experimental group compared with that of the control group. (a) Meta-analysis of $\mathrm{CD}^{+}$level in included studies. (b) The sensitivity analysis of the seven included articles.

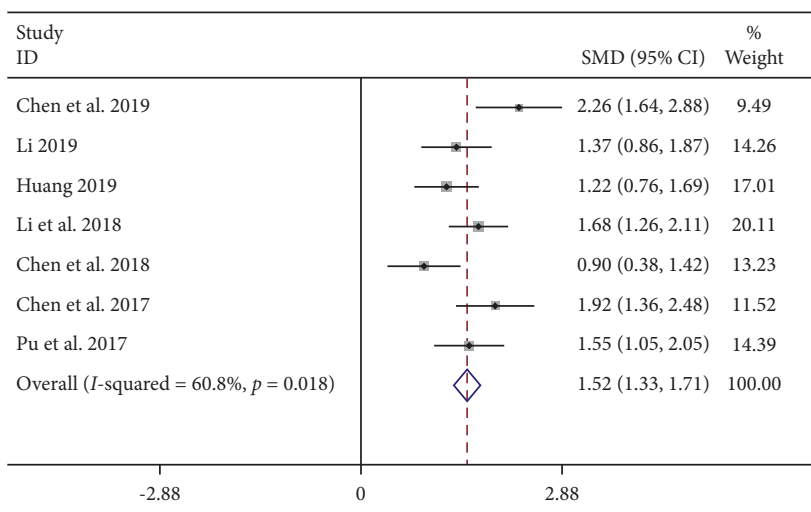

(a)

\begin{tabular}{ccccccc}
\hline$\_$ES & Coef. & Std. Err & $\mathrm{t}$ & $\mathrm{P}>|\mathrm{t}|$ & \multicolumn{2}{c}{$[95 \%$ Conf. Interval] } \\
\hline Duration (day) & 0.014816 & 0.0049854 & 2.97 & 0.031 & 0.0020006 & 0.0276315 \\
_cons & 0.6431747 & 0.3128499 & 2.06 & 0.095 & -0.1610317 & 1.447381 \\
\hline
\end{tabular}

(c)

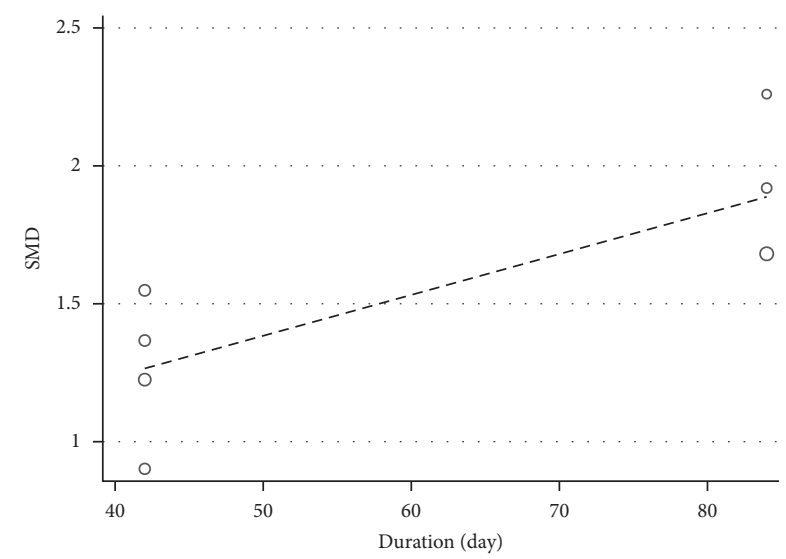

(b)

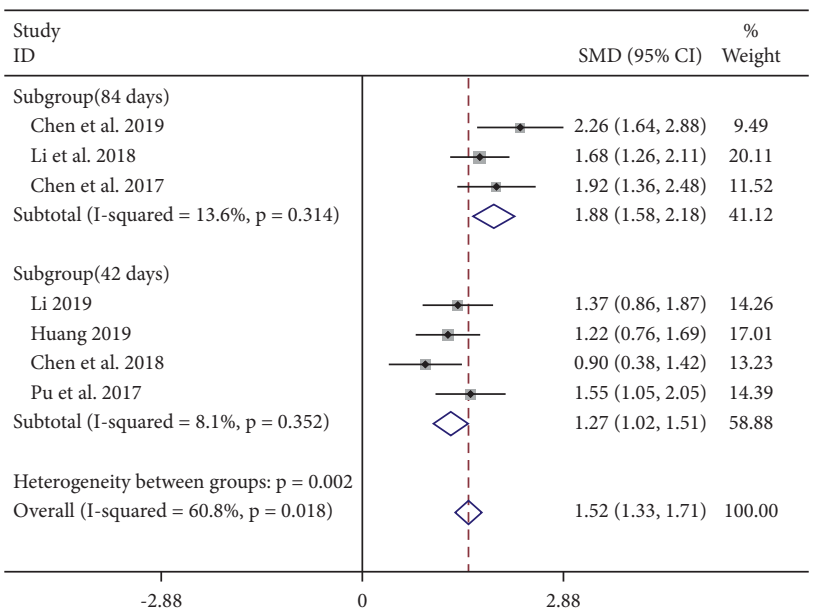

(d)

Figure 11: (a) Meta-analysis of $\mathrm{CD}^{+}$level in included studies. (b, c) The results of the meta-regression analysis. (d) The subgroup study of $\mathrm{CD}^{+}$level. 


\begin{tabular}{l|lll}
\hline Study \\
ID
\end{tabular}

(a)

\begin{tabular}{ccccccc}
\hline _ES & Coef. & Std. Err & $\mathrm{t}$ & $\mathrm{P}>|\mathrm{t}|$ & \multicolumn{2}{c}{ [95\% Conf. Interval] } \\
\hline dosage & 0.7715909 & 0.2080852 & 3.71 & 0.014 & 0.2366909 & 1.306491 \\
_cons & 1.008281 & 0.1394412 & 7.23 & 0.001 & 0.6498357 & 1.366726 \\
\hline
\end{tabular}

(c)

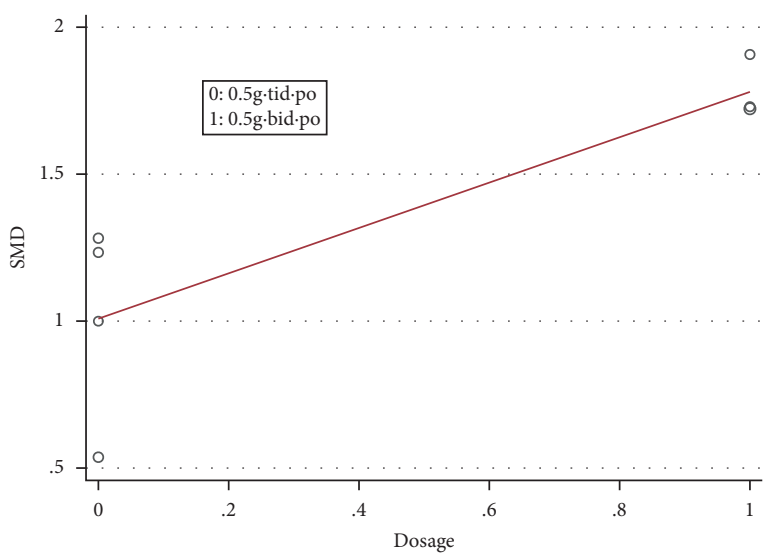

(b)

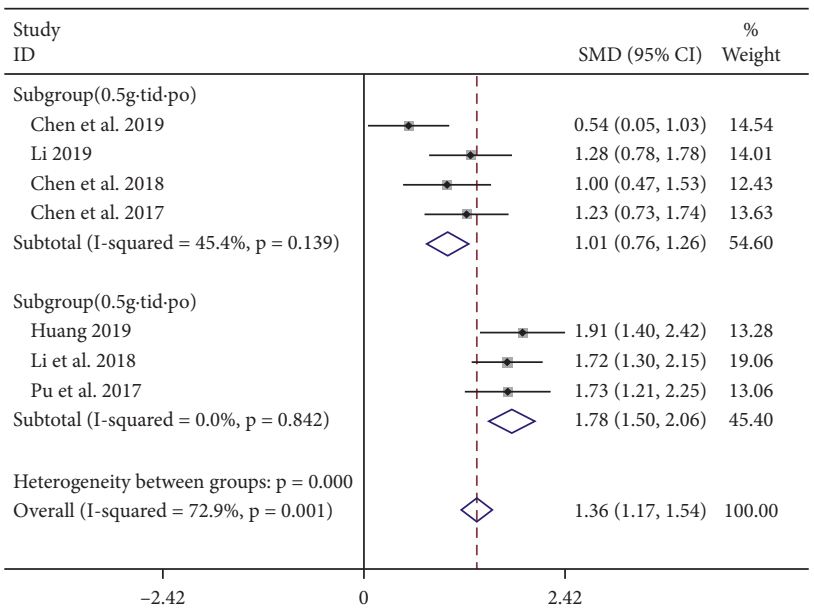

(d)

Figure 12: (a) Meta-analysis of $\mathrm{CD} 4^{+} / \mathrm{CD}^{+}$level in included studies. (b, c) The results of the meta-regression analysis. (d) The subgroup study of $\mathrm{CD}^{+} / \mathrm{CD} 8^{+}$level.

All of the included studies reported "patients were randomised into two groups;" however, of 19 trials, only 3 studies described the randomization procedure in detail, and none of them mentioned blind and concealment of treatment allocation which is very important for rigorously designed RCTs. It has been shown that clinical studies using inadequate methods of ensuring allocation concealment are more likely associated with significant results than those using adequate concealment [41]. In addition, it is essential for the authors to describe how the participants who are lost to follow-up will be handled and whether those participants are monitored in survival analysis [42]. However, none of the included studies reported this information, and no trials mentioned whether they had used intention-to-treat (ITT) analysis. Thus, this meta-analysis indicated existence of potential risks of selection bias, performance bias, and detection bias, which would result in the overestimation of the clinical efficacy in the cinobufacini capsule plus chemotherapy group. Funnel plots and Egger's test indicated that there was potential risk of publication bias; however, we have demonstrated the conclusion was stable by searching conference abstracts, taking the heterogeneity test, and carrying out the trim and fill method. Altogether, the potential benefits of cinobufacini capsule for advanced NSCLC patients need to be further assessed through rigorously designed RCTs.

As a traditional Chinese medicine, cinobufacini, an aqueous extract from the parotid gland of Bufo toad, is widely used as an adjuvant therapy for various cancers $[10,43-46]$. It has been reported that cinobufacini can reduce cell viability and induce genotoxicity and apoptosis in human lung cancer A549 cells in vitro [47, 48]. The extracted biologically active substance of cinobufacini mainly contains bufadienolides, alkaloids, and nucleosides $[47,49,50]$. It has been demonstrated that cinobufacini exerts the antitumor effect through many intracellular signaling mechanisms such as activating caspase- 3 activity, inhibiting the expression of MAP kinase, and elevating Fas/ Fasl and TNF-alpha/TNFR1 pathways [51, 52]. Resibufogenin, one of the components of cinobufacini, has been shown to inhibit the growth of A549 cells due to the degradation of cyclin D1 caused by the activation of glycogen synthase kinase-3 $\beta$ [53]. These biological characteristics of the active substance of cinobufacini might 
directly associate with the benefits to the NSCLC patients undergoing chemotherapy. Thus, these findings may provide evidence at the molecular level to support the clinical treatment with cinobufacini capsule for patients with NSCLC. However, to clarify the function of cinobufacin capsule as an adjunct to chemotherapy, future research focusing on the the bioactive components and specific mechanisms of cinobufacin capsule are needed. Furthermore, for future clinical research, it is essential to improve the methodological quality of RCTs and ensure that the reporting follows the CONSORT guidelines [42].

\section{Conclusions}

In summary, cinobufacini capsule combined with the firstline platinum-based chemotherapy regimen is superior to chemotherapy alone in the treatment of advanced NSCLC. However, the quality of the research included in this systematic review was not high, and the number of cases was small; this led to certain biases in the abovementioned conclusions. Therefore, it is necessary to design a large-scale, scientifically implemented large-scale study to strengthen the quality of research reports for the second evaluation. High-quality research studies should be provided to enhance the strength of the evidence in order to accurately guide clinical medication.

\section{Data Availability}

The data used to support the finding of this study are available from the corresponding author upon request.

\section{Disclosure}

Wenpan Peng and Yong Xu should be regarded as the cofirst authors.

\section{Conflicts of Interest}

The authors declare no conflicts of interest regarding the publication of this paper.

\section{Authors' Contributions}

$\mathrm{XZ}$ and $\mathrm{HH}$ contributed to conception and design of the study. WP searched the database, evaluated studies for inclusion, extracted data, and then, cross checked with YX. WP, YX, DH, and FF assisted in literature retrieval and data analysis. FF and ZW wrote the first draft of the manuscript. WP completed the final version. All authors contributed to the article and approved the submitted version.

\section{Acknowledgments}

The authors would like to thank Editage [http://www. editage.cn] for English language editing. This work was supported by the National Natural Science Foundation of China (Grant no. 82074358).

\section{References}

[1] R. L. Siegel, K. D. Miller, and A. Jemal, "Cancer statistics, 2020," CA: A Cancer Journal for Clinicians, vol. 70, no. 1, pp. 7-30, 2020.

[2] K. D. Miller, L. Nogueira, A. B. Mariotto et al., "Cancer treatment and survivorship statistics, 2019," CA: A Cancer Journal for Clinicians, vol. 69, no. 5, pp. 363-385, 2019.

[3] Z. Wang, F. Feng, Q. Wu et al., "Disodium cantharidinate and vitamin B6 injection adjunct with platinum-based chemotherapy for the treatment of advanced non-small-cell lung cancer: a meta-analysis," Evidence-Based Complementary and Alternative Medicine, vol. 2019, Article ID 9386273, 16 pages, 2019.

[4] P. Baxevanos and G. Mountzios, "Novel chemotherapy regimens for advanced lung cancer: have we reached a plateau?," Annals of Translational Medicine, vol. 6, no. 8, p. 139, 2018.

[5] A. Weissferdt, A. Pataer, A. A. Vaporciyan et al., "Agreement on major pathological response in NSCLC patients receiving neoadjuvant chemotherapy," Clinical Lung Cancer, vol. 21, no. 4, pp. 341-348, 2020.

[6] S. Chen, A. Flower, A. Ritchie et al., "Oral Chinese herbal medicine (CHM) as an adjuvant treatment during chemotherapy for non-small cell lung cancer: a systematic review," Lung Cancer, vol. 68, no. 2, pp. 137-145, 2010.

[7] Q. Wang, Q. Wang, S. F. Wang et al., "Oral Chinese herbal medicine as maintenance treatment after chemotherapy for advanced non-small-cell lung cancer: a systematic review and meta-analysis," Current Oncology (Toronto, Ont.), vol. 24, no. 4, pp. e269-e276, 2017.

[8] F. Qi, A. Li, L. Zhao et al., "Cinobufacini, an aqueous extract from Bufo bufo gargarizans Cantor, induces apoptosis through a mitochondria-mediated pathway in human hepatocellular carcinoma cells," Journal of Ethnopharmacology, vol. 128, no. 3, pp. 654-661, 2010.

[9] Z. Meng, P. Yang, Y. Shen et al., "Pilot study of huachansu in patients with hepatocellular carcinoma, nonsmall-cell lung cancer, or pancreatic cancer," Cancer, vol. 115, no. 22, pp. 5309-5318, 2009.

[10] J. Qi, C. K. Tan, S. M. Hashimi et al., "Toad glandular secretions and skin extractions as anti-inflammatory and anticancer agents," Evidence-Based Complementary and Alternative Medicine, vol. 2014, Article ID 312684, 11 pages, 2014.

[11] Y. Xu, D. Han, F. Feng et al., "Meta-analysis of cinobufacini Injection combined with platinum-contained first-line chemotherapy in treatment of non-small cell lung cancer," China Journal of Chinese Materia Medica, vol. 44, no. 21, pp. 4728-4737, 2019.

[12] K.-Q. Han, G. Huang, W. Gu et al., "Anti-tumor activities and apoptosis-regulated mechanisms of bufalin on the orthotopic transplantation tumor model of human hepatocellular carcinoma in nude mice," World Journal of Gastroenterology, vol. 13, no. 24, pp. 3374-3379, 2007.

[13] J.-Y. Yeh, W. J. Huang, S.-F. Kan, and P. S. Wang, "Effects of bufalin and cinobufagin on the proliferation of androgen dependent and independent prostate cancer cells," The Prostate, vol. 54, no. 2, pp. 112-124, 2003.

[14] M. Watabe, Y. Masuda, S. Nakajo, T. Yoshida, Y. Kuroiwa, and K. Nakaya, "The cooperative interaction of two different signaling pathways in response to bufalin induces apoptosis in human leukemia U937 cells," Journal of Biological Chemistry, vol. 271, no. 24, pp. 14067-14073, 1996. 
[15] R. Huang and Y. Su, "Clinical efficacy of cinobufacin capsules combined with chemotherapeutic drugs in the treatment of non-small cell lung cancer: a meta-analysis," Clinical Medication Journal, vol. 16, no. 5, pp. 59-63, 2018.

[16] H. He, X. Zhou, Q. Wang, and Y. Zhao, "Does the couse of astragalus-containing Chinese herbal prescriptions and radiotherapy benefit to non-small-cell lung cancer treatment: a meta-analysis of randomized trials," Evidence-Based Complementary and Alternative Medicine, vol. 2013, Article ID 426207, 11 pages, 2013.

[17] H. Jpt and P. MJ, "Cochrane handbook for systematic reviews of interventions," 2020.

[18] M. K. Palmer, "WHO handbook for reporting results of cancer treatment," British Journal of Cancer, vol. 45, no. 3, pp. 484-485, 1982.

[19] Y. Xu, W. Peng, D. Han et al., "Combined treatment of nonsmall-cell lung cancer using shenyi capsule and platinumbased chemotherapy: a meta-analysis and systematic review," Evidence-based Complementary and Alternative Medicine: eCAM, vol. 2020, Article ID 3957193, 9 pages, 2020.

[20] C. W. Gu, "The combination of estimates from different experiments," Biometrics, vol. 10, no. 1, pp. 101-129, 1954.

[21] M. Egger, G. D. Smith, M. Schneider, and C. Minder, "Bias in meta-analysis detected by a simple, graphical test," British Medical Journal, vol. 315, no. 7109, pp. 629-634, 1997.

[22] Z. Su, "Clinical study of Huachansu capsule combined with GP chemotherapy in the treatment of 44 patients with advanced non-small cell lung cancer," Chinese Journal of Convalescent Medicine, vol. 28, no. 6, pp. 629-631, 2020.

[23] M. Li, R. Chen, B. Ji et al., "The clinical efficacy and prognosis of cinobufacini combined with GP regimen in the treatment of advanced non-small cell lung cancer," Journal of Chinese Physician, vol. 20, no. 12, pp. 1844-1846, 2018.

[24] Q. Chen, H. Xu, and J. Liu, "The efficacy of Cinobufacini capsule combined with DP chemotherapy in the treatment of advanced non-small cell lung cancer," Journal of Clinical Research, vol. 36, no. 3, pp. 556-558, 2019.

[25] Z. Li, "Cinobufacini capsule combined with DP chemotherapy in the treatment of advanced NSCLC," Henan Medical Research, vol. 28, no. 12, pp. 2244-2246, 2019.

[26] M. Huang, "Clinical observation of Huachansu combined with GP chemotherapy in the treatment of advanced nonsmall cell lung cancer," Practical Clinical Journal of Integrated Traditional Chinese and Western Medicine, vol. 19, no. 6, pp. 51-52+127, 2019.

[27] S. Lan, L. Gao, and J. Yan, "Effect of cinobufagin capsule combined with PC chemotherapy on serum tumor marker level and life quality in patients with advanced NSCC," Journal of Clinical Psychosomatic Diseases, vol. 24, no. 2, pp. 84-87, 2018.

[28] Q. Chen, M. Zhang, X. Li, and B. Zhang, "Clinical observation of cinobufacini capsule combined with chemotherapy in the treatment of advanced non-small cell lung cancer," Modern Journal of Integrated Traditional Chinese and Western Medicine, vol. 27, no. 9, pp. 984-987, 2018.

[29] T. Yu, F. Chen, D. Cheng, and J. Li, "Clinical effect and safety of Cinobufacini Capsules combined with chemotherapy in the treatment of advanced non-small cell lung cancer," China Modern Medicine, vol. 25, no. 35, pp. 53-55, 2018.

[30] J. Liu, "Clinical observation of Huachansu capsule in adjuvant treatment of non-small cell lung cancer," Journal of China Prescription Drug, vol. 16, no. 9, pp. 73-74, 2018.

[31] J. Chen, X. Ma, D. Wei, and C. Wang, "Impact of cinobufacini capsule combined with PC chemotherapy on immunological function, serum CA125 level and survival time of patients with advanced non - small cell lung cancer," Practical Journal of Cardiac Cerebral Pneumal and Vascular Disease, vol. 25, no. 9, pp. 162-164, 2017.

[32] J. Pu, P. Lu, and Y. Pan, "Effects of cinobufacini capsule combined with NP chemotherapy on serum CYFRA21-1, NSE levels and immune function in advanced NSCLC patients," Journal of Hubei University of Chinese Medicine, vol. 19, no. 1, pp. 26-29, 2017.

[33] W. Shi, "The effect of Huachansu capsule combined with chemotherapy on non-small cell lung cancer," Guide of China Medicine, vol. 15, no. 5, pp. 179-180, 2017.

[34] G. Wei and C. Xu, "Efficacy of different chemotherapy regimens for advanced non-small cell lung cancer," Chinese Journal of Clinical Oncology and Rehabilitation, vol. 24, no. 2, pp. 167-169, 2017.

[35] J. Chen, X. Hu, S. Huang, L. Qin, and X. Wang, "Effects of cinobufagin capsule combined with GP protocol on immune function in patients with advanced non-small cell lung cancer," China Modern Doctor, vol. 54, no. 14, pp. 12-15, 2016.

[36] W. Li, J. Cui, J. Wang, and J. Wang, "Clinical observation of bronchial arterial infusion chemotherapy combined with cinobufacini capsule in the treatment of advanced non-small cell lung cancer," China Pharmacy, vol. 26, no. 26, pp. 3703-3706, 2015.

[37] X. Xiao, Q. Mei, Y. Li, Y. Wei, and S. Wang, "Cinobufacini capsule combined with chemotherapy in treatment of patients with advanced lung cancer," Journal of Practical Oncology, vol. 30, no. 5, pp. 469-473, 2015.

[38] B. Liu, "Observe the clinical effect of cinobufacin capsules in the treatment of small cell lung cancer," Journal of Clinical and Experimental Medicine, vol. 13, no. 15, pp. 1263-1265, 2014.

[39] X. Miao, H. Cao, and W. Wang, "The observation of the shortterm effect of Huachansu capsule combined with TP regimen in the treatment of advanced non-small cell carcinoma," Chinese and Foreign Medical Research, vol. 12, no. 28, pp. 131-133, 2014.

[40] J. Li, "Cinobufotalin piece combination chemotherapy for advanced non-small cell lung cancer," Chinese Journal of Medicinal Guide, vol. 13, no. 11, pp. 1907-1908, 2020.

[41] C. Hewitt, S. Hahn, D. J. Torgerson, J. Watson, and J. M. Bland, "Adequacy and reporting of allocation concealment: review of recent trials published in four general medical journals," British Medical Journal, vol. 330, no. 7499, pp. 1057-1058, 2005.

[42] D. Moher, S. Hopewell, K. F. Schulz et al., "CONSORT 2010 explanation and elaboration: updated guidelines for reporting parallel group randomised trials," International Journal of Surgery, vol. 10, no. 1, pp. 28-55, 2012.

[43] T.-J. Qin, X.-H. Zhao, J. Yun, L.-X. Zhang, Z.-P. Ruan, and B.-R. Pan, "Efficacy and safety of gemcitabine-oxaliplatin combined with huachansu in patients with advanced gallbladder carcinoma," World Journal of Gastroenterology, vol. 14, no. 33, pp. 5210-5216, 2008.

[44] Z. Meng, C. R. Garrett, Y. Shen et al., "Prospective randomised evaluation of traditional Chinese medicine combined with chemotherapy: a randomised phase II study of wild toad extract plus gemcitabine in patients with advanced pancreatic adenocarcinomas," British Journal of Cancer, vol. 107, no. 3, pp. 411-416, 2012.

[45] Y. Jiang, L. Wu, L. Shen et al., "Effect of traditional Chinese medicine treatment as maintenance therapy on regulating the serum concentration of sCTLA- 4 in patients with advanced 
non-small-cell lung cancer and its relationship with prognosis," Chinese Journal of Oncology, vol. 38, no. 10, pp. 757-762, 2016.

[46] Y. Jiang, L.-S. Liu, L.-P. Shen et al., "Traditional Chinese Medicine treatment as maintenance therapy in advanced nonsmall-cell lung cancer: a randomized controlled trial," Complementary Therapies in Medicine, vol. 24, pp. 55-62, 2016.

[47] L. Wang, U. Raju, L. Milas et al., "Huachansu, containing cardiac glycosides, enhances radiosensitivity of human lung cancer cells," Anticancer Research, vol. 31, no. 6, pp. 21412148, 2011.

[48] S. Lee, Y. Lee, Y. J. Choi, K.-S. Han, and H. W. Chung, "Cyto-/ genotoxic effects of the ethanol extract of Chan $\mathrm{Su}$, a traditional Chinese medicine, in human cancer cell lines," Journal of Ethnopharmacology, vol. 152, no. 2, pp. 372-376, 2014.

[49] H. Zhao, X. Wu, H. Wang et al., "Qualitative and quantitative analysis of cinobufacini injection using rapid separation liquid chromatography coupled with quadrupole-time-of-flight mass spectrometry and HPLC-photodiode array detection, a feasible strategy for the quality control of Chine," Journal of Separation Science, vol. 36, no. 3, pp. 492-502, 2013.

[50] X. Wei, N. Si, Y. Zhang et al., "Evaluation of bufadienolides as the main antitumor components in cinobufacin injection for liver and gastric cancer therapy," PLoS One, vol. 12, no. 1, Article ID e0169141, 2017.

[51] E. T. Efuet, X.-P. Ding, C. Cartwright, Y. Pan, L. Cohen, and P. Yang, "Huachansu mediates cell death in non-Hodgkin's lymphoma by induction of caspase- 3 and inhibition of MAP kinase," International Journal of Oncology, vol. 47, no. 2, pp. 592-600, 2015.

[52] T. Yang, R. Shi, L. Chang et al., "Huachansu suppresses human bladder cancer cell growth through the Fas/Fasl and TNF- alpha/TNFR1 pathway in vitro and in vivo," Journal of Experimental \& Clinical Cancer Research, vol. 34, no. 1, p. 21, 2015.

[53] M. Ichikawa, Y. Sowa, Y. Iizumi, Y. Aono, and T. Sakai, "Resibufogenin induces G1-phase Arrest through the proteasomal degradation of cyclin D1 in human malignant tumor cells," PLoS One, vol. 10, no. 6, Article ID e0129851, 2015. 